Portland State University

PDXScholar

\title{
Explaining Unequal Transportation Outcomes in a Gentrifying City: the Example of Portland, Oregon
}

\author{
Eugenio Arriaga Cordero \\ Portland State University
}

Follow this and additional works at: https://pdxscholar.library.pdx.edu/open_access_etds

Part of the Transportation Commons, and the Urban Studies Commons Let us know how access to this document benefits you.

\section{Recommended Citation}

Arriaga Cordero, Eugenio, "Explaining Unequal Transportation Outcomes in a Gentrifying City: the Example of Portland, Oregon" (2017). Dissertations and Theses. Paper 3509.

https://doi.org/10.15760/etd.5393

This Dissertation is brought to you for free and open access. It has been accepted for inclusion in Dissertations and Theses by an authorized administrator of PDXScholar. Please contact us if we can make this document more accessible: pdxscholar@pdx.edu. 
Explaining Unequal Transportation Outcomes in a Gentrifying City:

The Example of Portland, Oregon

by

Eugenio Arriaga Cordero

A dissertation submitted in partial fulfillment of the requirements for the degree of

\title{
Doctor of Philosophy \\ in \\ Urban Studies
}

\author{
Dissertation Committee: \\ James Strathman, Chair \\ Amy Lubitow \\ José Padín \\ Liming Wang
}

Portland State University

2017 


\begin{abstract}
This dissertation examines unequal outcomes of urban transportation policies in the neoliberal era. It focuses on inequalities in the Portland, Oregon metro area between 1994 and 2011 as measured in three key areas: 1) access to public transit; 2) the journey-towork; and 3) "household-serving" trips. Growing concern over the harmful impacts from an increasing dependence on cars has led planners in the U.S. to encourage a modal shift from private car to public transit, bicycling, and walking. The required policies to make this modal shift possible, however, might inadvertently be benefiting 'choice' riders at the cost of transport disadvantaged groups. Other contributing factors to this unequal benefit appear to be the suburbanization of poverty, an ongoing gentrification of central areas, and market forces that make it difficult for low income groups to afford housing in transit-rich neighborhoods. The Oregon Household Activity and Travel surveys are used to answer the three major research questions in this dissertation: what has been the effect of neoliberalism on access to public transit?; how do gender, race/ethnicity, and income inequality affect the journey-to-work in Portland?; and how do household-serving trips vary by gender in Portland? Six hypotheses are tested in answering these questions. Those related to access to transit draw on Fred Block's theory of the capitalist state and the "urban growth machine" concept, both of which predict spatially unequal outcomes from neoliberal policies. Hypotheses about the journey to work draw on a rich body of literature around social relations in the household and the job market, as well as residential location. The final question, about household-serving trips, draws on theories
\end{abstract}


of gender socialization. Findings showed that: (i) individuals in the Portland metro area had less access overall to bus public transit in 2011 than in 1994; (ii) impoverished dependent riders have lost access to transit service over time, as compared to choice dependent riders; (iii) low income groups have been 'forced' into greater car-ownership, in part due to their reduced access to public transit; (iv) women in Portland have shorter journey-to-work trips than men; (v) Blacks have longer journey-to-work trips than Whites and Latinos; (vi) low-income individuals have shorter journey-to-work trips than higher income individuals; and (vii) women with children make more household-serving trips than men in similar family structures. 


\section{Dedication}

To my beloved wife Karin and my children Luciana and Eugenio, and my mentor and friend, Judy. I could not have done it without your help. Thank you for all your support along the way. 


\section{Acknowledgments}

I would like to express my special appreciation and thanks to my advisor Professor James Strathman, you have been a remarkable mentor for me. I would like to thank you for encouraging my research and for allowing me to grow as a transportation scholar and researcher. Your advice on both research as well as on my career have been very important for me. I would also like to thank my committee members, Professor José Padín, Professor Amy Lubitow, Professor Liming Wang for all your help, support and for serving in my dissertation committee. I also want to thank you for your brilliant comments and suggestions. In addition, I would like to thank all the other faculty in Urban Studies and elsewhere who supported my work, specially professor Jennifer Dill. All of you have been there to support me when I needed it.

A special thanks to my family for all your help. Words cannot express how grateful I am to my children Luciana and Eugenio. Your support for me helped me come this far. I would also like to thank my special friends Judy Walton and Stephen Frenkel, who supported me in so many ways to strive towards my goal, I am truly thankful to both of you. Also to my friends Joe Broach and Liang Ma, who always helped me.

At the end I would like express appreciation to my beloved wife Karin who was always my support in the moments when there was no one else. 


\section{Table of Contents}

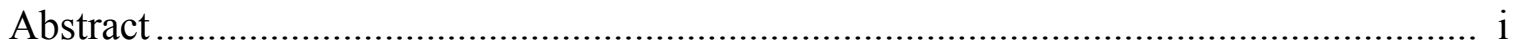

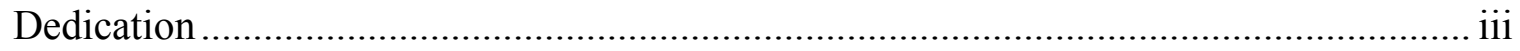

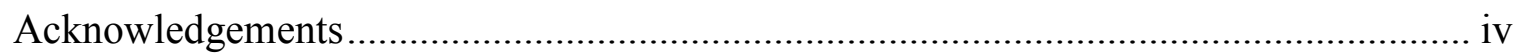

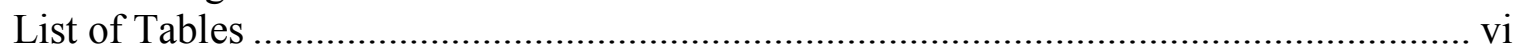

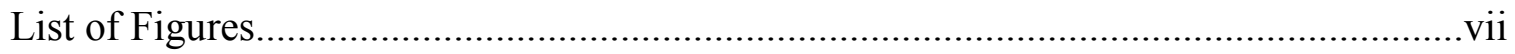

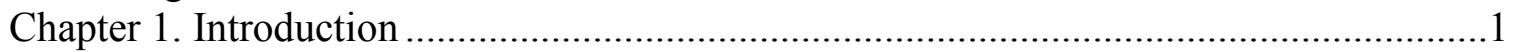

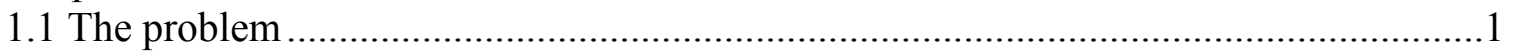

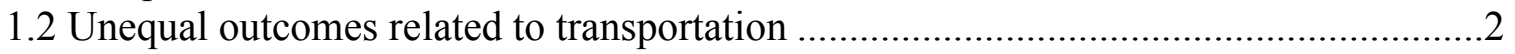

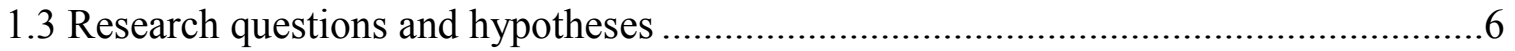

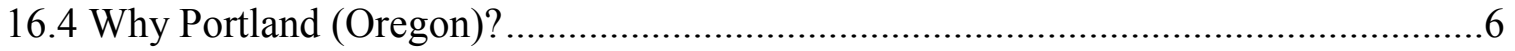

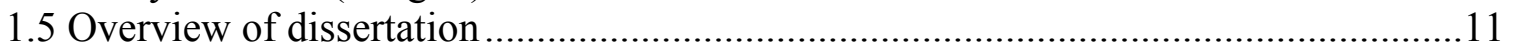

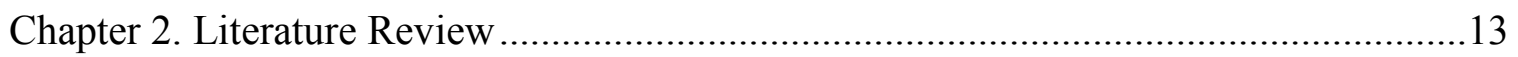

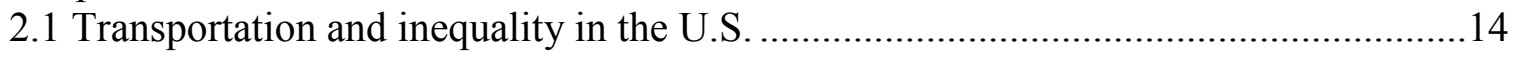

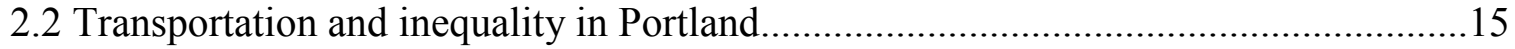

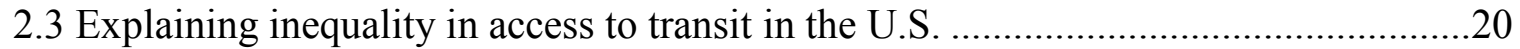

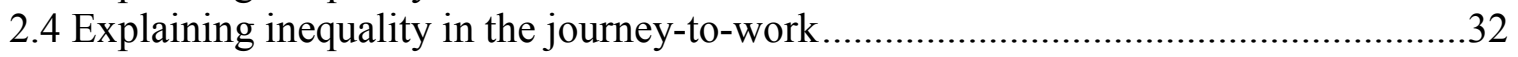

2.5 Explaining inequalities in household-serving trips..............................................48

Chapter 3. Research Design: Questions, Hypotheses, Data and Methodology .................53

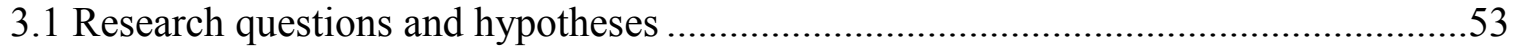

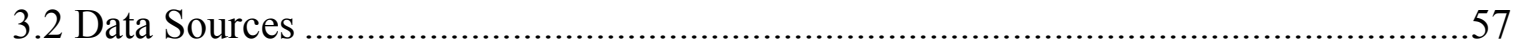

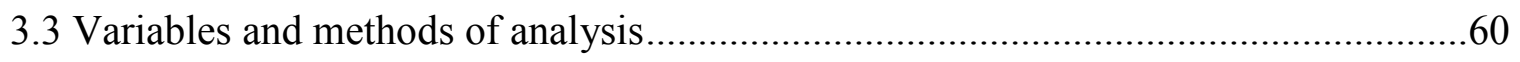

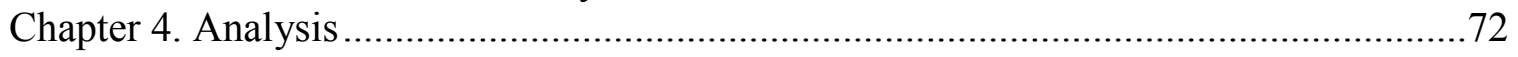

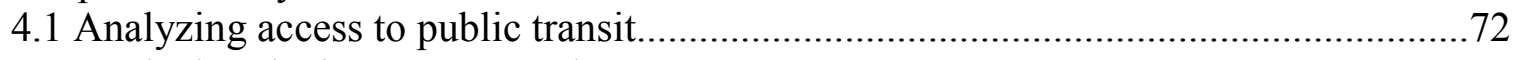

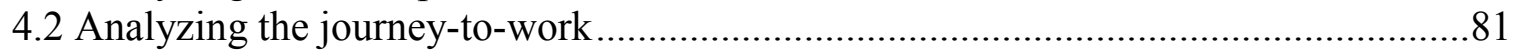

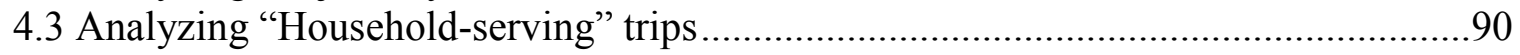

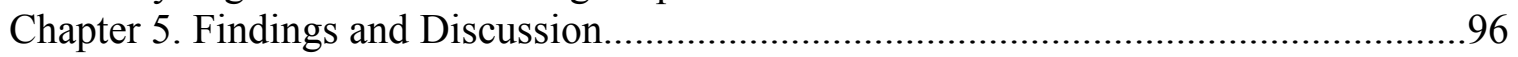

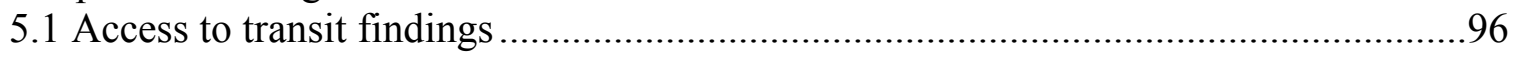

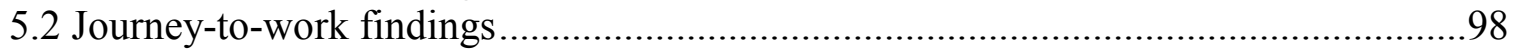

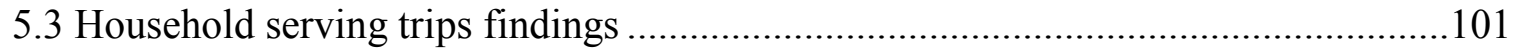

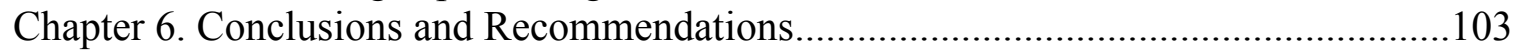

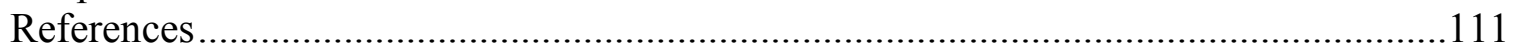

Appendix. Socio-Demographic Trends in the Portland Metropolitan Area.............. 123 


\section{List of Tables}

Table 1: Factors of social exclusion and their relationship to transportation ............ 46

Table 2. Findings of empirical studies of gendered travel behavior by family structure. 49

Table 3. Dependent variables in the study for the access to transit analysis............. 61

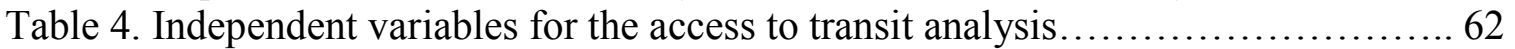

Table 5. Mobility group characteristics...................................... 63

Table 6. Dependent variables for the journey-to-work analysis....................... 66

Table 7. Independent variables for the journey to work analysis ..................... 67

Table 8. Dependent variables for the household-serving trips analysis...................68

Table 9. Independent variables for the household-serving trips analysis...............69 69

Table 10. Number of unique public transit routes within 500 meters from home in 1994

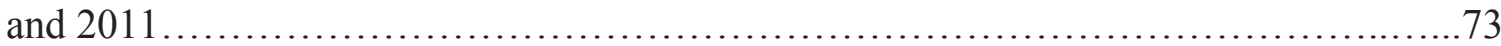

Table 11. Distance to nearest public transit station from home in 1994 and 2011........74

Table 12. Number of transit lines per Mobility Group in years 1994 and 2011 ...........77

Table 13. Number of frequent service lines per Mobility Group in $2011 \ldots \ldots \ldots \ldots \ldots . \quad 77$

Table 14. Distance to nearest transit stop from home per Mobility Group in years 1994

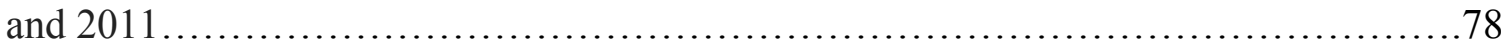

Table 15. Means of transport to work by race/ethnicity, Portland 2000 and $2013 \ldots \ldots \ldots . .80$

Table 16. Driving alone regressed on period of time ............................... 81

Table 17. Journey-to-work distance regressed on gender, race, income and year .........84

Table 18. Journey-to-work time regressed on gender, race and income................ 84

Table 19. Journey-to-work time regressed on gender, race and income ................ 85

Table 20. Journey-to-work distance regressed on gender, race and income............ 85

Table 21. Journey-to-work distance regressed on income, period of time and race.......90

Table 22. Journey-to-work time regressed on income, period of time and race ...........90

Table 23. Number of household-serving trips regressed on household type by gender....93

Table 24. Household-serving trip time regressed on household type by gender...........93

Table 25. Household-serving trip distance regressed on household type by gender.......94 


\section{List of Figures}

Figure 1. Mobility groups' conceptualization chart.............................64 


\section{Chapter 1. Introduction}

\subsection{The problem}

Growing concern over the harmful environmental and social impacts from an increasing dependence on cars has led transportation planners in the U.S. to encourage a shift from private car use to public transit, bicycling, and walking. These efforts aim to turn drivers into "choice riders" (i.e., individuals who could drive but choose to ride transit instead), which means the city must provide an effective substitute for the private car. However, rather than improving the quality of bus service, many cities have placed more focus on rail transit infrastructure. Two key reasons for the focus on rail transit investment are that it is considered more attractive to choice riders (Giuliano, 2005), and it helps to attract private investment, which cities in the neoliberal era actively seek. Research by Glaeser et al. (2008) and Baum-Snow et al. (2005) found that rail transit expansion in major cities in the U.S. was explicitly designed to connect central city areas to richer suburbs - thus serving many choice riders - and not to improve access in poor areas.

At the same time, as shown by Grengs (2005), many cities are experiencing a changing residential pattern in which low-income residents are being priced out of central cities while higher-income residents increasingly occupy the core. Since public transit investment has focused on the core (and wealthier suburbs), one would expect that the new, higher-income residents in the central city would have greater levels of access than the growing number of low-income, suburban residents. Further, lower levels of transit 
investment in outer neighborhoods and low-income suburbs - particularly in bus systems - have increasingly forced many residents to own a car. This includes individuals who were transit-dependent in the core, but are no longer served by public transit in the suburbs, and thus have to purchase a car. Therefore, this dissertation argues that neoliberal transit policies in such cities, heavily focused on rail infrastructure investments and other means of shifting drivers to public transit, succeed largely at the cost of those who rely on transit the most.

\subsection{Unequal outcomes related to transportation}

This study of the Portland metropolitan area seeks to investigate some of the unequal outcomes of transportation policies in the neoliberal era. Specifically, it looks at inequalities in: 1) access to public transit; 2) the journey-to-work; and 3) "householdserving” trips

\section{Inequality in access to public transit}

Access to transit is analyzed through two political economic frameworks that are critical of neoliberal policy: namely, Logan and Molotch's concept of "city as a growth machine," and Fred Block's theory of the capitalist state. The analysis focuses particularly on inequalities among different income groups in their access to public transit.

Neoliberal ideology, which advocates for the extension of market-based principles in order to reduce state "inefficiencies," has shaped public transit in significant ways. 
Beginning sometime in the 1980s, a neoliberal turn accelerated the shift in transit policy from its original purpose of providing transportation as a public service toward a narrower, economic-based purpose of relieving traffic congestion while increasing efficiency (Grengs, 2005). Farmer (2013) shows in detail how mass transit's original purpose - to provide a public good for those left out by the market - has been undermined under neoliberalism by this new logic of monetary efficiency.

While neoliberal ideology might explain this shift to economic efficiency on a policy scale, it is important to look at the agents behind the policies. Fred Block's capitalist state theory (1977) focuses on state managers as the key actors in designing and implementing neoliberal policies, which largely benefit business interests. Public agency leaders have few incentives to pursue anti-capitalist policies in part because they see their own continued power as dependent on a "healthy business climate" (p.8). This means maintaining economic and political order. Since extending the state's role (such as by expanding public services) would likely increase the corporate tax burden and lead to a decline in business confidence, agency heads and other "state managers" become averse to such a goal.

With respect to transit, therefore, we would expect public officials to avoid investing tax dollars in bus infrastructure, particularly in low-income, outer neighborhoods and suburbs, since it would mean a larger governmental role - with associated higher operating costs and more employees, and a potential negative reaction by businesses. The only circumstance preventing local governments from completely privatizing or 
neglecting transit systems is that special characteristics of the transportation sector force the government to own most of the fixed infrastructure. Since the private sector will not (or can not) provide public transit - which is generally indispensable to people without access to a car - the government is expected to provide this public good (Deen, 2003).

While Block's state theory (and other political theories of the state) help explain the disinvestment in public transit in general, there is another mechanism at work that is useful in understanding geographically unequal transportation outcomes within a city (as well as between cities). In "The City as a Growth Machine" (1976) Harvey Molotch posits that elites who make money off land will act to promote urban investments that increase the attractiveness of a place for further investment. He identifies a central conflict in cities between elites, or "rentiers" - who are pursuing exchange value from land and form a consensus called a "growth machine" - and residents, who are more concerned with use values. Along with his collaborator John Logan, he argues that this conflict "closely determines the shape of the city, the distribution of people, and the way they live together" (Logan and Molotch 1987, p.2). In terms of public transportation, the growth machine concept would explain why light rail infrastructure is implemented in some areas - where elites have a vested interest in real estate development - and not others. This idea in general helps explain how inequalities within and between cities are established and maintained.

\section{Inequality in the journey-to-work}


The commute to work can serve as a good indicator of inequalities in job and housing markets in a city. Differences in the "journey-to-work" variable by race/ethnicity, income, and gender offer a lens to explore the forces at work that lead to unequal outcomes. Since neither state theory nor the growth machine concept directly address gender, race, and income inequality, it was necessary to extend the theoretical framework used in analyzing access to transit in order to explore journey-to-work differences. Particularly relevant in this case are the bodies of theory around "social relations in the household and job market," "residential location," and "social exclusion" (MacDonald, 1999; Lucas, 2010; Massey, 1996). These will be described in the literature review.

\section{Inequalities in "household-serving” trips}

The third indicator used in this dissertation to examine urban inequality from the lens of transportation was "household-serving" trips - errands and other non-work trips that benefit members of a household. Differences in the number, duration, and distance of such household-serving trips among different groups can reveal much about the forces at work in producing uneven outcomes in a city. Gender differences are particularly relevant when looking at household-serving trips because they can illuminate inequalities within the household.

Similar to the journey-to-work analysis, the analysis of household-serving trips required going beyond the political-economic theories of place in order to incorporate a gender lens. The analysis therefore draws on the literature around gender inequality and 
transportation. In particular, it examines theories about "gender socialization." These concepts will be explored further in the next chapter.

\subsection{Research questions and hypotheses}

The three major research questions in this dissertation relate to the three key transportation metrics described above. The first question is related to access to transit, and asks: "What has been the effect of neoliberalism on access to public transit in metropolitan Portland?" Two hypotheses are tested here (which will be described in the research design chapter). They are based on Block's theory of the capitalist state and Molotch's concept of the city as a growth machine.

The second research question, related to the journey-to-work, asks: "How do gender, race/ethnicity, and income inequality affect the journey-to-work?" Three hypotheses are tested here (described in the research design chapter), each drawing on one of the following bodies of theory: a) social relations in the household and job market, b) residential location, and c) social exclusion, as described in the literature review.

The final research question is: "How does gender inequality affect household-serving trips in Portland?" The hypothesis tested for this question draws on theory around "gender socialization," as described in the literature review and research design chapters.

\subsection{Why Portland (Oregon)?}


The metropolitan area of Portland, Oregon was selected for case study analysis for a number of inter-related reasons.

First, in Portland, neoliberal ideology and the workings of the growth machine have been clearly manifested in the city's urban renewal program over the past two decades (this program is described in detail in the literature review chapter). Rising land values in Portland's urban core in the 2000's were actively bolstered by, if not a direct outcome of, city policies and programs. Portland now finds itself on the leading edge of a housing affordability crisis, exacerbating spatial inequalities.

Rising rents and home prices have been pushing low-income, transit-dependent people toward outer neighborhoods and suburbs. Transit agencies have been unwittingly contributing to this process through their focus on improving transit service in the urban core, where density is greatest and ridership is high, at the cost of service in outer neighborhoods and suburbs. These improvements include enhanced bus service as well as new rail transit.

The result in Portland is a geographic marginalization of the city's lower income and minority populations, who find themselves living in the urban periphery where transit service is more limited and expensive. As in other cities, transit services in Portland are not following lower-income groups to the suburbs. Instead, as this dissertation will show, Portland's growth machine elites remain focused on increased service in places where ridership is high (i.e., politically connected inner neighborhoods). While "choice riders" (who take transit by choice, not by need) are increasing in number in Portland due to 
explicit policies that favor them, the needs of transit-dependent populations are being ignored. The city therefore offers a good case study of the consequences of urban policies that drive up land values in the core.

A second reason for selecting Portland for analysis is that it was one of the earliest cities in the U.S. to adopt a sustainable transportation approach; so there has been sufficient time to observe the consequences, both intended and unintended. In fact, this early adoption of sustainable transportation goals and policies is a key factor behind Portland's identity as a sustainable, vibrant, and walkable city - a topic explored below. And with a regional population growing at well above the U.S. metropolitan average, the consequences of Portland's policies, plans, and programs are likely to be evident sooner than would be the case elsewhere.

Third, and related to the above, years of local research and analysis of transportation outcomes in the city and region have resulted in abundant data being available. This research tapped into some of that data, described in the research design chapter.

A fourth and final reason for studying Portland is that while the city is often considered a quirky, outlier, it has also become a role model for an increasing number of cities. Cities throughout the country have been looking to Portland as a sustainable urban development leader (tied into its identity, discussed below), and are seeking to emulate its focus on building a vibrant, livable core. Portland has been a national leader in the coordination of transportation and land use, with land use policies that encourage higher development densities, and urban renewal programs that integrate redevelopment with transit. Other 
cities can learn from Portland's successes and mistakes as they seek to imitate its compact, mixed-use core and transit-oriented development.

\section{The Portland identity}

As indicated above, Portland's urban identity is an important reason why other U.S. cities are looking to learn from its example. Portland is a very special place. It is in fact difficult to find a similar city within the United States: It has the highest bicycle rates for a city of its size; it has an unusually large urban park and park system; and it is the only place in the country with an elected regional government. It is well known for its urban growth boundary, mandated by a statewide system for land use planning. Portland is even the subject of a TV show, Portlandia, that gently mocks its eccentricities.

For many years Portland has been at the top of urban life quality rankings in the USA. It is one of the few U.S. cities that makes regular appearances on lists of the nation's best managed cities (Abbott 2001: 4). Portland has been continuously praised by planners, geographers and architects who have portrayed the city in their books as an example of successful urban development and metropolitan planning. Vice President Al Gore described Portland as "the best of all possible worlds, where quality-of-life planning has stimulated rather muffled economic growth" (Abbott, 2001: 6). The reason for all this praise, according to local urban scholar Carl Abbott, is that "Portland comes close to matching an emerging model of good urban form: it assigns high value to the maintenance of strong downtowns in order to nurture cultural vibrancy, promote social cohesion, and support nationally competitive advance service industries" (2001: 5). 
That said, not all outcomes are positive: Abbott noted as early has 2001 how Portland had transformed, losing a number of interesting social features over time. He lamented the displacement of artists to the periphery of the city as property values rose.

\section{$\underline{\text { Portland's civic engagement and urban planning reputation }}$}

Portland has been recognized since the 1970s for its strong civic engagement. According to Abbott, the city has a history of "strong public involvement in both grassroots environmentalism and neighborhood conservation" (2001:4). The tremendous success in planning experienced by the city of Portland would probably not exist if it were not for its culture of public involvement. As noted by Abbott, the Portland area "benefits from more than seventy-five 'Friends of..."” organizations - i.e., civic organizations monitoring development matters and advocating for restoration projects. Portland also holds nearly 25 community development corporations and more than 100 neighborhood associations that are community-controlled but city-sponsored (Abbott, 2001: 4). According to Abbott, the city's "eclectic urbanists" have borrowed theoretical components from other urbanists and intellectuals, such as Jane Jacobs, William S. Whyte and John Stuart Mill, to emphasize the values of civic action in public spaces, and social and cultural diversity.

In terms of political culture, metropolitan Portland is also well known for treating "land use planning, with its restrictions on private actions, as a legitimate expression of the community interest." The city has a strong interest in environmental design as a planning goal, borrowing from Frederick Law Olmsted's and Lewis Mumford's visions of “cities and towns interlacing with the natural and cultivated environments." In terms of 
cityscape and urban form, Portland has been able to "bring environmentalism and urbanism together in a coherent package of mutually supportive planning and development decisions" (Abbott, 2001: 6). This includes its public transportation and land use decisions. Abbott argues that the progressive core and many suburbs have united around the idea of a compact city (2001: 211), which has contributed to Portland's recognition for the importance its citizens place on the physical environment.

All of these factors have combined to give Portland its identity as a "green city," a "progressive city," and a successful example of urban planning. Of course, as in many other cities, Portland's current success is the cause of multiple planned and unplanned processes. Paradoxically, Portland's slow economic growth in the 1960s and 1970s, and stability in the economically depressed 1980s, allowed it to preserve elements from each decade, giving it a unique urban character. Nevertheless, the city is undergoing great social and economic changes, and experiencing a tension between the growing industrial, technological and innovation sectors and a steadier, greener lifestyle (Abbott, 2001: 206).

\subsection{Overview of dissertation}

This introductory chapter is followed by a literature review that explores the relationships between transportation and inequality in the U.S. and reviews a number of explanatory theories, especially those focused on differences in access to transit, the journey-to-work, and household-serving trips. This is followed by a chapter on research design, which reviews the three main research questions and lays out the related hypotheses for each, along with the theories they draw on. It then introduces the data and variables used in the 
study and articulates the research methodology and methods of analysis. Next, an analysis chapter describes how the hypotheses were tested using statistical methods and discusses the findings and their meaning in the context of the relevant theories. The dissertation ends with a summary of key findings and conclusions in answering the research questions. 


\section{Chapter 2. Literature Review}

This chapter examines the literature on concepts and theories related to unequal outcomes of transportation policies and urban planning. It focuses on three aspects of transportation: 1) Access to public transit, 2) Journey-to-work, and 3) "Householdserving" trips. Specifically, it reviews the research relevant to answering the three key questions of this dissertation:

1. What has been the effect of neoliberalism on access to public transit in metropolitan Portland?

2. How do gender, race/ethnicity, and income inequality affect the journey-to-work in Portland?

3. How does gender inequality affect household-serving trips in Portland?

To understand the first question - the effect of neoliberalism on inequalities in access to public transit - this chapter examines the literature on neoliberal ideology, theories of the capitalist state, and city-as-growth-machine. These concepts are used in later chapters to interrogate two hypotheses on inequality in access to public transit among different income groups in Portland. Other relevant concepts, such as the role of poverty in transportation, and the concepts of "transportation disadvantage" and "forced-car ownership," are also examined here.

For the second topic - differences in the journey-to-work by gender, race/ethnicity, and income - this chapter reviews the literature on bodies of theory around: "social relations in the household and in the job market," "residential location," and "social exclusion." 
These theories are used in the analysis chapter to test three hypotheses about differences in the journey-to-work in Portland based on gender, race/ethnicity, and income level.

For the last research question - how gender inequality affects household-serving trips in Portland - the literature around "gendered socialization" is reviewed, as it is later used to investigate a key hypothesis related to this question.

Before delving into the literature on specific research questions, this chapter begins with a review of transportation and inequality in the U.S. in general, and in Portland, since these contexts are central to answering all three research questions. It includes a look at the literature on gentrification and displacement in the Portland metropolitan area, especially with respect to how it may be exacerbating the challenges for transportdisadvantaged groups.

\subsection{Transportation and inequality in the U.S.}

The subject of inequality in urban transport and mobility is not new within the transportation literature. Since the 1970's researchers have been interested in the topic (Lucas, 2012; Currie, 2007). As early as 1973, Wachs and Kumagai identified physical mobility as a major contributor to social and economic inequality in the U.S. context. By the 2000's, researchers and policy makers were extensively examining social inequities in transportation in the context of environmental justice (e.g., Cervero et al., 2002; Handy et al., 2005; Lucas, 2006; Sen, 2008; Wachs, 2010). 
An important focus of the literature on the relationship between inequality and transportation is how "transport disadvantage" can lead to the social exclusion of lowincome individuals and communities. A number of studies have aimed to make more explicit the links between income, access to transportation and key services, and ability to participate in life enhancing opportunities (Church and Frost, 2000; Lucas et al., 2001; Kenyon 2003; Kenyon et al., 2003; Hine and Mitchell, 2003; Hodgson and Turner, 2003; Rajé, 2004).

These studies have increased our understanding of how inadequate provision of public transportation decreases mobility for many individuals, which leads to further social exclusion of already socially disadvantaged individuals (Lucas et al., 2001, Hine and Mitchell, 2003). Travel offers access to opportunities, which in turn affect one's quality of life (Lucas, 2012).

\subsection{Transportation and inequality in Portland}

\section{Urban renewal}

Over the last few decades in Portland, as described by Goodling et al. (2015), urban renewal funds have resulted in rising property values and an incoming wave of wealthier, mainly White residents to Portland. These changes have come about, in part, from the installation of public transit and bike infrastructure, in an effort to attract affluent, welleducated, environmentally minded residents along with businesses that cater to their tastes. During the 1960s and 1970s, urban renewal projects displaced Black residents and 
businesses in order to redevelop the city. Between the 1970's and 1990's, city officials lured capital back to the central city through the development of important infrastructure projects. This period encompasses the City's annexation of a large amount of East Portland's land and residents - and tax base - and the continued devaluation of Black neighborhoods (Goodling et al.,2015).

By the 1970s, middle-class taxpaying households were moving to the suburbs. As a response, according to Goodling et al. (2015), city officials justified urban renewal projects that continued to affect African American neighborhoods. The implication was that Portland's "livability" was hindered by the presence of certain groups. In 1991, the city of Portland used public funds, through Albina's Interstate Corridor Urban Renewal Area (URA) tax-increment financing, to improve the largely African-American district's streets, and sidewalks (Gibson, 2004). A central feature of the Interstate URA was a light rail line, which later contributed to the gentrification of the area.

\section{Gentrification and involuntary displacement}

Portland has been able to control sprawl through land-use policies (including an urban growth boundary) that promote, compact, mixed-use, and transit-oriented development. In particular, access to public transit (Brueckner et al., 2009), and topographical and historical amenities in the city center (an attractive river or beachfront), as posited by Brueckner et al., (1999) contribute to attract the rich more strongly than the poor, leading to a Paris-style location pattern. Eventual redevelopment of aging dwellings in the center 
creates a young downtown housing stock that attracts high-income households, leading to gentrification.

However, Portland's success in creating an attractive central city might be producing unintended consequences by contributing to the rising costs of housing in the central area. Among these consequences are neighborhood gentrification and the displacement of long-time working-class residents from in-city neighborhoods (Lang and Hornburg, 1997; Abbot, 1997; Soja, 2010).

In Portland, Black neighborhoods have had a long history of disinvestment, which ended in (and in many ways led to) gentrification and involuntary displacement during the 1990s (Gibson, 2004, 2007, 2013). McKenzie (2013) suggests that the trend of displacement of Blacks is expected to continue in the near future, as evidenced by the fact that the dissimilarity index ${ }^{1}$ for Blacks increased from $47 \%$ in 2000 to $51 \%$ in 2009 . Although Blacks have accounted for about 3\% of the Portland population since 1990 (see Appendix, Table 1), their residential location has shifted during this time: between 1990 and 2010 the proportion of Blacks living at the periphery ${ }^{2}$ of the city increased (see Appendix, Table 2), while the population of Blacks living in the city and close-in communities (the area encompassed by Multnomah County), decreased from $5.9 \%$ of the total population in 1990 to $5.4 \%$ in 2010 .

\footnotetext{
${ }^{1}$ The dissimilarity index is a demographic measure of the evenness with which two groups are distributed across component geographic areas that make up a larger area.

${ }^{2}$ The term "periphery" refers to neighborhoods in the suburban counties of Clackamas and Washington
} 
Gibson (2007) shows that after over 40 years of being segregated in the Albina district (as a result of federally-backed redlining and exploitative practices of speculators, slumlords, bankers, and real estate agents) Blacks began to be displaced by affluent newcomers in the 1990s. Between 1990 and 2010, Albina lost more than 6,000 Black residents to areas in the periphery of the city, where housing is cheaper but basic services and amenities are lacking relative to other areas of the city.

Since 2000, areas of poverty in Portland have shifted from the city center to the suburban communities (McKenzie, 2013). During this period housing costs (and rents) have increased in the central city (Miles and Song, 2009), particularly affecting renters who often need to move to less expensive neighborhoods (Shaw and Sullivan, 2011).

It may be that growing poverty among Blacks in Portland (in 2013 they had the highest share of any racial group below poverty, at $34 \%$ ) contributes to explaining the increasing share of Blacks living at the periphery of the city. Although growing poverty rates among racial minorities and a decreasing population of Blacks in Multnomah County cannot in itself count as evidence of gentrification or involuntary displacement of racial minorities (from transit-rich neighborhoods to transit-poor neighborhoods in the periphery of the Portland metro area), this is a plausible hypothesis supported by research (McKenzie, 2013; Gibson, 2004, 2007, 2013). These trends suggest that at the very least the Black residential location pattern has changed since the 1990s, and that perhaps it has become very difficult for low-income Blacks to afford living in central city neighborhoods in Portland. 
Latinos in Portland have followed a different growth pattern than Blacks. From 1990 to 2010, the Latino proportion of the population increased from $3.4 \%$ to $11.7 \%$ (see

Appendix, Table 1). In contrast to Blacks, Latinos growth has been distributed evenly in all three counties of metropolitan Portland (see Appendix, Table 2).

\section{Changes in public transit}

During the 1980's, transit lost a larger share of the market in metropolitan Portland than in most regions of the country (from 8 percent to 5 percent, and among Portland's employed residents, from 16 percent to 11 percent) (Cervero, 1998). In the 1990's downtown Portland's transit modal split for work trips exceeded 40 percent of total trips, attributable to two decades of targeted efforts aimed at revitalizing the core (Cervero, 1998).

Anbinder (2015) found that transit service mileage was reduced between 2006 and 2012 in Portland by more than $10 \%$. One explanation may be that the transit market share of all trips has dropped during the last 20 years from $8.4 \%$ to $6.0 \%$ - in other words, since Portlanders are using transit less, service has been reduced. This means access to transit is also reduced. Access to transit for both Blacks and Latinos in Portland declined between 2000 and 2010, with Latinos having the relatively poorest access to transit (McKenzie, 2013). 
The remaining sections of this chapter review the literature on inequality related to each of the three key aspects examined in this dissertation: access to transit, journey-to-work, and household-serving trips.

\subsection{Explaining inequality in access to transit in the U.S.}

\section{Neoliberalism}

One of the key questions this dissertation explores is the effect of neoliberalism on access to public transit in Portland. Neoliberalism is an ideology that sees human well-being as best advanced by liberating individual freedoms within an institutional framework of strong private property rights, free markets, and free trade (Harvey, 2007). The politicaleconomic practice of neoliberalism started in Chile in the early 1970s and soon spread as a new economic orthodoxy; by 1979 it was adopted in the U.S. Neoliberal doctrine is associated with economists Milton Friedman and Friedrich Hayek, who deeply opposed state interventionist theories such as those of John Maynard Keynes. As a consequence of neoliberal policies in the U.S. deregulation, privatization, and, most important, withdrawal of the state from many areas of social provision have been all too common.

Scholars, including Farmer (2013), Marcuse and van Kempen (2000), and Grengs (2004), show how the neoliberal political project is characterized by its efforts at reducing the social welfare state, cutting costs, deregulating business activity, privatizing previously public spaces and activities, and engaging in new forms of social control. According to Soja (2010) this happens due to the pressures faced by entrepreneurial cities to compete 
with investments and tourism in the global economy, rather than dealing with poverty and uneven development.

The public provision of transit service offers a great opportunity to examine the impacts of neoliberalism. Stephanie Farmer (2013) shows how neoliberal ideology has shaped the possibilities of constructing public transit in the U.S., and asserts: "The concrete and specific features that make mass transit useful as an urban transit mode are curtailed, distorted and undermined by a logic of monetary efficiency [under neoliberalism] that tends to reduce the variegated features of urban mass transit to an abstract, generalized, interchangeable, pecuniary cash nexus" (p.62).

Sometime in the 1980s, Farmer argues, public transit in the U.S. began shifting from its earlier purpose of providing a public service toward a narrower, economic purpose focused on such goals as relieving traffic congestion and increasing efficiency. This neoliberal policy turn has negatively impacted urban bus systems in particular, with an increased focus on routes that pay for themselves, in places where ridership is high (i.e., the urban core), and a turn toward rail investment rather than bus.

As Grengs (2004) laments, planners seem to have lost sight of the public purpose of mass transit. The social goal of providing mobility is being displaced by the economic goal of reducing congestion. This undermines the original purpose of providing adequate transit for those who have no other option, and further illustrates how meeting human needs in the neoliberal era becomes subordinate to the imperatives of capital accumulation. 
Grengs goes on to point out that transit planners are facing a growing dilemma: should transit serve people who have few transportation choices, or should it offer drivers an alternative to their cars? He asks if current transit policies are hurting social equity, and whether public transit should be considered a means for advancing larger social goals; and argues strongly that it should.

Neoliberalism has impacted transit at the federal level as well. Farmer (2013) cites three ways in which neoliberal policy shaped federal transit support: 1) by reducing funding, 2) by allowing states the flexibility to distribute funds, and 3) by phasing out federal daily operations subsidies.

Therefore, despite the technical efficacy of mass transit systems, they are embedded in a capitalist economy and state that tend to undermine that efficiency by cutting funding. This leads to insufficient maintenance of buses and trains, which in turn produces longer travel and wait times for riders. It also leads to decreased access to public transit service, which has been cut back deeply in low-income communities where many minorities live.

The market-driven placement of transit lines tends to create an irrational transit network where access to mass transit is uneven, with redundant service in some neighborhoods and a lack of service in others (Yago, 1984). Differential access to transportation infrastructure reduces the cost of living for some workers - those living in transit-rich neighborhoods can save both time and money - while increasing it for others. 
According to Farmer (2013) neoliberal austerity in the late 1990s also included a more aggressive stance towards organized labor in the public transit sector. Nationwide, new policies reduced overtime, scaled back employee healthcare plans, reduced worker's compensation payments, cut the number of conductors operating trains, encouraged hiring part-time and non-union security personnel to staff the busiest train platforms, and reduced the number of bus supervisors whose job was to ensure that buses were running on time.

\section{The Chicago example}

Chicago offers an excellent example of neoliberal ideology at work. In their study of the development of the mass transit system in Chicago, Farmer and Noonan (2014), showed how capitalism distorts and degrades the urban mass transit system in a manner that is favorable for the accumulation of capital, but goes against satisfying people's need for an effective and efficient urban transportation.

By the 1980s in Chicago, public mass transit - which had been sustained through progressive tax policies - was redefined as anti-competitive and too costly under ascendant neoliberalism. The imposition of a 50\% farebox recovery mandate required the transit system to generate $50 \%$ of operations revenue from rider fares, concessions, advertising and investments (Anderson, 2004, p.3).

The criteria for cost effectiveness was based on whether operation costs were recovered or surpassed by revenues collected on a route, which ignored the wider external social 
costs of curtailing public transit service. The Chicago Transit Authority (CTA) shifted from a focus on providing useful transit service to privileging a logic of "fiscal constraint," where transit service is subservient to exchange-value. The $50 \%$ farebox recovery policy was essentially a cut in the social wage, driving up the cost of living for the working class.

In addition, the federal government eliminated its $\$ 40$ million subsidy for public transit operations in Chicago between 1995 and 1998 for the sake of fiscal austerity (Farmer and Noonan, 2014). The resulting drop in ridership was used to justify the next round of service cuts, yielding reduced ridership that was used, in turn, to justify future cycles of cuts, creating a vicious cycle of recursive austerity. In this way, the neoliberal state externalizes the costs of public transit onto the backs of public transit riders.

The consequences of such policies in Chicago are now obvious: The physical quality of the rail system has declined, while the bus system has been curtailed, strained and understaffed. Public transit service has deteriorated, both in terms of the safety of the system and in terms of the system's size and frequency of buses and trains (i.e., reduced access).

The predominantly Black and Latino neighborhoods of the south and west sides of Chicago have seen their access to transit curtailed the most, while the Loop's residential and office markets have been growing, with transit a key amenity supporting their development. The presence of good mass transit attracts "desirable" firms to move to the area (Farmer and Noonan, 2014). 
As the literature and this case study show, the interaction between mass transit as a usevalue, the logic of the circuits of capital, and the social power of exchange-value produces highly contradictory effects and perverse outcomes. One goal of this research was to test whether Portland would resemble Chicago in terms of increased inequality in access to transit under a neoliberal paradigm (McKenzie, 2013).

\section{Growth machine theory}

Harvey Molotch's “city as a growth machine" metaphor (1976) provides a political economic framework to critique neoliberal ideology. This theory offers a credible explanation of how spatial inequities in transportation systems are produced and maintained. According to his theory, the political and economic essence of localities is growth $^{3}$ and the desire for growth provides the key motivation toward consensus around urban development among local elites, who all profit from land. They compete with other land-based elites to have growth-inducing resources invested within their own area; and they use their governmental connections to influence decisions affecting land-use and public budget.

A central conflict in cities, as explained in the introduction, is thus between "rentiers," who are pursuing exchange values, and residents, who are more concerned with use values. This conflict, argue Logan and Molotch $(1987$, p.2) "closely determines the

\footnotetext{
${ }^{3}$ The indicator of successful growth is "rising urban-area population". The way it works is: initial expansion of basic industries, followed by an expansion of the labor force, a rising scale of retail and commerce, increasingly intensive land development, higher population density, and increased levels of financial activity.
} 
shape of the city, the distribution of people, and the way they live together." Lowincome neighborhoods are particularly vulnerable to the reorganization of urban space in the pursuit of exchange values, as Melissa Gilbert shows (in Jonas and Wilson, 1999, p. 97).

Applied to urban and public transportation, growth machine theory explains both past and present development of transportation systems. As Clark (1983, p. 272) demonstrates: "transportation systems in the U.S. were not built primarily to provide transportation but to sell real estate." From the beginning, the laying out of mass transit lines was a method of stimulating development; and transit officials tended to favor growth along their specific transit routes. "Indeed, the land speculators and the executives of the transportation firms were often the same people" (Logan \& Molotch, 1987, p.74).

This highlights the close relationship between transportation and real estate development that persists today. Logan and Molotch go on to explain: "Transit bureaucrats... function as active development boosters; only in that way can more riders be found to support their systems and help pay off the sometimes enormous debts incurred to construct or expand the systems" (p.74). As a consequence, transportation doesn't just serve growth, it creates it.

An example is the heavy focus on rail infrastructure investment in U.S. cities. All the elements of the growth machine are at work here. First, local elites form a consensus around rail transit investment due to its likelihood of increasing nearby land values and rents (much more so than bus infrastructure). Second, light rail construction benefits the 
private sector through private-public partnerships and construction contracts - again, more so than bus infrastructure. Third, driving all this are new, wealthier urbanites who prefer riding light rail and streetcars over buses and are able to advocate for them using their political connections. The inevitable result is rising rents resulting from the new rail infrastructure; which in turn negatively affects low-income residents, who may no longer be able to afford to live in these neighborhoods. This appears to be the case in Portland, Oregon, as the analysis chapter will show.

\section{Capitalist state theory}

Whereas traditional Marxist theory roots the explanation of capitalist rationality in the consciousness of the ruling class, an alternative political economy framework offered by Fred Block in "The Ruling Class Does Not Rule” (1977) provides a new way of thinking about the sources of rationality within capitalism - one that focuses on the "state managers" themselves. Block suggests that "even in the absence of ruling-class class consciousness, state managers are strongly discouraged from pursuing anti-capitalist policies" (p.8), as described in the Introduction chapter. Thus they will act in the best interests of the capitalist state.

Block posits that public officials ("managers of the state apparatus") see their own continued power as dependent on maintaining a "healthy business climate," which means maintaining economic and political order, as mentioned in the Introduction one way of doing this is by keeping corporate taxes low. Business confidence tends to decline in the 
face of efforts to extend the state's role because it would mean an increased tax burden on businesses.

In terms of transit policy, this would explain why public officials support rail-transit infrastructure over bus infrastructure: the former facilitates private investment; and private investors have power to influence state managers to give them infrastructure contracts. Bus infrastructure, on the other hand, does not enable private investment, and instead requires increased bureaucracy, higher operation costs, and a larger government role, which leads to a higher tax burden and a less friendly business climate.

\section{The role of poverty in travel behavior}

Income is strongly related to travel behavior: people with low incomes travel much less (and have lower levels of mobility) than those with higher incomes. As Hanson (2010) argues, class is central to assessing equity in mobility and access to transit. Mauch and Taylor (1997) suggest that income might matter even more than gender in understanding travel behavior, because lower income groups share common economic and social characteristics, and have similar occupations and residential locations, all of which affects their travel behavior.

Income affects an individual's choice of residential location and their ability to afford a car (Doyle et al, 2000). Low-income individuals rely more on transit and carpooling due to their inability to afford a car. Low mobility level and unemployment (or underemployment) are connected: the availability, speed, and price of public 
transportation may significantly and adversely affect employment opportunities for people with low earnings capability. Transportation and welfare studies (Blumenberg and Hess, 2003) show that without adequate transportation, welfare recipients face significant barriers in trying to move from welfare to work. These challenges are particularly acute for urban mothers who do not own cars and must make multiple trips each day to accommodate childcare and other domestic responsibilities.

Existing public transportation systems cannot always bridge the gap between where the poor live and where jobs are located. These systems were originally established to transport inner-city residents to city locations and bring suburban residents to central city work locations. However, the majority of the entry-level jobs that the poor would be likely to fill are located in suburbs that have limited or no accessibility through existing public transportation systems. Furthermore, many entry-level jobs require shift work in the evenings or on weekends, when public transit services are either unavailable or limited (Sanchez, 2008).

Thus, the location of jobs and workers and the existing transportation network within metropolitan labor markets may explain lower levels of transit access and high unemployment among the poor.

\section{Forced car-ownership}

Banister (1994) defines the term "forced car-ownership" to mean situations where there are not adequate substitutes for gaining access to the places where people need to go; thus 
the car becomes a necessity. According to Jones (2011) there are various degrees of car dependence based either on the characteristics of individuals (e.g., people with disabilities) or of trips (e.g., trips where there are no alternative forms of transportation; destinations that are not served by alternative modes of transport; activities that cannot be undertaken without a car; and trip-chaining, requiring multiple stops for different purposes).

Public policies have historically acted to encourage car-centric development patterns such as out-of-town shopping and housing developments and the siting of key facilities such as hospitals and colleges away from urban centers, which makes them harder to serve with public transport. As such, people without cars simply cannot keep pace with the rising need to travel in order to carry out essential activities.

In auto-oriented landscapes it is not realistic to assume that large groups of individuals will use transit, particularly those currently driving, or even those who apparently would benefit from it. Access to a car provides several benefits: it contributes to enhanced earnings since driving facilitates access to jobs (Blumenberg and Hess, 2003); and it offers greater ease in carrying out daily activities, particularly for households with children (Raphael and Rice, 2002; Cervero and Tsai, 2003). In this context it makes sense that most low-income households in the U.S. might aspire to own a car to enjoy the higher levels of mobility, accessibility, convenience, and flexibility that automobile ownership affords. 
That said, growing car ownership among the poorest households is also in part due to the lack of access to adequate transit service, which forces low-income individuals into driving to obtain the mobility that a car provides. It is in this sense that the poor are "forced" into car-ownership. As asserted by Giuliano (2005), if reliable and safe transit service were readily available and moderately priced, more poor people would use transit and forgo the costs of car ownership.

In this dissertation the concept of "forced car-ownership" is used to describe households with limited means to afford car use, but where no alternatives are available, as defined by Banister (1994) and Jones (1987). Forced car-ownership emphasizes the lack of transportation options available to disadvantaged populations in an automobile-oriented landscape, which "forces" them to own a car (Banister, 1994; Wickham and Lohan, 1999). It is important to note that forced car-ownership does not deny the obvious benefits of cars, but highlights the fact that these benefits come at the cost of significant financial challenges for low-income groups.

Gleeson and Randolph (2002) referred to the financial stress created by owning and running a car as "transport poverty," which occurs when a household is forced to consume more travel costs (i.e., car ownership and usage) than it can reasonably afford. Transport poverty is magnified in places like the U.S. where owning a car is more of a necessity due to land-use patterns. Poor people who own cars expend a greater proportion of their income on maintaining their cars, reducing their capacity to consume other goods. Clifton and Lucas (2004) delineate the financial burdens that low-income 
households face in purchasing, operating and maintaining vehicles. Thus, the direct costs of transport contribute to higher living expenses among low-income populations.

Financial sacrifices tend to be especially high among low-income, suburban residents who generally have fewer transportation options and thus depend more on automobiles.

They have larger fuel-cost burdens due to the need to travel longer distances (which may in part be due to few affordable housing options in close-in neighborhoods). Adding yet another layer of disadvantage, forced-car-owners tend to restrict the use of their car to reduce maintenance and fuel costs, resulting in missed opportunities (Currie and Senbergs, 2007; Stanley, 2004).

\section{Forced car-ownership among minorities}

Crane (2007) showed that the largest increase of car users since 1985 has been among Latino and Black women. It makes sense that poor single parents, mostly females, seem to be induced into "forced car-ownership" due to child responsibilities that may not be conducted by transit.

Deka (2004) posits that in the U.S., Blacks and Latinos (over-represented among the poor) increased their household expenditure on transportation between 1992 and 2002 by $62.5 \%$ and $45.5 \%$, respectively, based on 2004 dollars. Over time, from 1988 to 2008 , the transportation-expenditure burden declined 14\% among all households but increased 1\% among households in the bottom income quintile.

\subsection{Explaining inequality in the journey-to-work}


Work trips are considered the most relevant link between housing and labor markets, and thus the journey-to-work may say a lot about unequal access to both. The research focus on journey-to-work in the 1970s through 1990s was a consequence of women's increase in the paid labor force during the 1960's (Tivers, 1978). Pratt and Hanson (1991) measured the journey-to-work as home-to-work time, distance, and cost. Journey-to-work studies in the 1990s and 2000s found that women's spatial range of mobility was smaller than men's (Hanson, 2010). This section reviews the literature on differences in the journey-to-work by gender, race/ethnicity and income level. A body of theories around "social relations in the household and in the job market" is reviewed with respect to gender differences in the journey-to-work. Another body of theory around "residential location" is explored as it pertains to racial/ethnic differences in the journey-to-work. And finally, theories around social exclusion are reviewed as they relate to income differences in the journey to work.

The next section discusses the most common mechanisms of inequality that contribute to explain gender differences in the journey-to-work.

\section{Gender differences in the journey-to-work}

During the 1960's, research looking at women's journey-to-work became more frequent (Tivers, 1978). According to Law (1999), after feminists questioned the planners' conventional assumption of the 'neutral commuter,' path-breaking research from Rosenbloom (1978) and Giuliano (1979) advanced our knowledge of gendered differences in travel behavior. 
Many of the studies above, not surprisingly, found consistent and significant gender differences in all aspects of the journey to work: trip distance, travel time, transport mode, and linkages among trips (Erickson, 1977; Hanson and Hanson, 1981; Madden, 1981). However, according to Hanson (2010) these studies were later criticized for ignoring relations of power, cultural contexts, lived experience, the importance of identities, and the different meanings of mobility.

While some studies showed that women traveled shorter distances to employment sites than men (Crane, 2007) other studies showed that not all women have shorter work trips than men (Law, 1999; Hanson, 2010; MacDonald, 1999; Gossen and Purvis, 2005; Theriault, et al, 2006). For example, McLafferty and Preston (1991) found no gender differences among Black and Latino female commuters. However, Rosenbloom (2006) and Crane $(2007,2009)$ showed that women's commute trips are still consistently shorter than the average man's for all races, although Rosenbloom (2006) noticed that the gender gap within each ethnic and racial group was greater than between whites.

\section{Social relations in the household}

The literature has been shown that unequal social relations in the household lead to an unequal division of labor (Taylor et al, 2015; Crane, 2007, 2009; Rosenbloom, 2006; Caumont, 2014). Women with partners still do the majority of household chores, even in dual-earner households (Madden, 1981). Women's higher share of household responsibilities contributes to explaining a shorter journey-to-work, because it is argued 
that shorter work-trips enable women to coordinate their activities as workers and housewives (MacDonald, 1999).

The gendered division of household work has been associated with feminist concepts (e.g., 'gender roles') to explain gender differences in travel (Law, 1999; Gavron, 1966; Cichocki, 1980; Forer and Kivell, 1981; Lopata, 1981; Tivers, 1985). These studies often operationalize gender roles through: domestic responsibilities, effects of marriage, effects of spousal employment, and the presence of children. For example, Pickup $(1984,1988)$ used "gender role" (measured as family role playing, gender related tasks, and conditions under which women travel) to explain women's lower mobility. His approach was criticized because the concept of "sex role playing" omitted constraints on mobility located in gender relations outside the home (e.g., gender pay gap) and because it implied equivalence, consensus, and choice, rather than power and coercion.

Research shows that the presence of children and having a partner is associated with disproportionate parenting and household responsibilities for women who still do the majority of household and childcare chores, even in dual-earner households (Taylor et al, 2015; Crane, 2007, 2009; Rosenbloom, 2006; Caumont, 2014). Hanson (2010) found that women's travel is largely a factor of their domestic and child-care responsibilities, as shown by Tivers (1985), who pointed out that including constraints faced by mothers of young children and housewives was a useful corrective to earlier urban studies that neglected women's experiences, and Madden (1981), who found that women work closer 
to their homes because their household responsibilities increase the cost of longer commutes.

Rosenbloom (2006) found that married women's total weekly housework is two to three hours higher than for all women; the amount of time devoted to household chores in households with children under 11 is three times more for wives than for husbands, independent of employment status; and even women who earn more than their husbands do more housework (Taylor, 2015).

As posited by Kwan (1999), having to balance employment with household responsibilities complicates women's schedules and reduces their travel distance options. As a consequence, women have tighter time budgets that generate complex time-space constraints during the daytime working hours as opposed to men, who have fewer family and household obligations.

The division of housework (e.g., household tasks and child care) is considered a powerful predictor of travel demand, because it reveals the reasons why trips to particular places are made at certain times (Law, 1999). Therefore, gendered differences in travel can be seen as a factor of gendered household activity patterns. In this context, Rapino (2011) posits that if women's and men's domestic responsibilities were equal, so would be their commuting patterns.

\section{Social relations in the job market and workplace}


Women face inequalities in the job market and workplace. Research shows that women earn less, work in different occupations and industries, and work shorter hours (Madden, 1981), are more likely to work in low-paid service jobs and, in general, experience various forms of discrimination in the labor market (Taylor, 2015; MacDonald, 1999; Rosenbloom, 2006). Women, on average, earn less than men and are more likely to be employed part time. In 2005 women accounted for two-thirds of all part-time U.S. workers, although only $25 \%$ of U.S. working women were employed part time. In addition, almost $60 \%$ of women (of all races) are employed in low paid and intermittent service-sector jobs, in traditional "female" occupations (Rosenbloom, 2006; Taylor, 2015). It follows that working women are more likely to be below poverty than working men. And finally, almost $40 \%$ of women workers do not have a day-shift job (one in which at least half of their work hours are between 8:00 a.m. and 4:00 p.m.). Thus, as posited by Madden (1981) women's shorter work trips are affected by their workplace activities and a discriminatory job market.

Not all women are affected in the same way; there are differences by race and class. For example, although women of color are as likely to work full-time as White women, they are more likely to have low-wage service jobs. Working mothers in particular pay a price in lower wages, reduced lifetime earnings, and minimal pensions because of part-time and interrupted work (Lorber, 2010).

Inequalities in the job market have negative transportation consequences for women. MacDonald (1999) explained women's travel behavior as a factor of their unequal work 
conditions. She argued that: (i) since women tend to hold low-paid, part-time jobs, they find it harder to justify long commutes, in part due transportation costs; Madden (1981) made a similar argument: women select jobs closer to their residences because their lower wage rates and shorter work hours reduce the earnings return to their commuting; (ii) women are more likely to find employment closer to home because the service sectors in which they tend to work are more evenly distributed (e.g., retail, education, or health), or decentralized to cheaper suburban office park locations (closer to suburban women), reflecting a gendered occupational segmentation (Hanson and Pratt 1995); and (iii) women's labor markets are spatially segmented by race, skill level, and gender. In some occupations and industries, local labor markets operate as "ghettos" of female employment, providing a concentration of low-wage, female-dominated jobs (Hanson et al, 1995; England, 1993).

In addition to gender inequalities in the journey to work, there are also racial/ethnic and income inequalities. The next section looks at these racial/ethnic differences in the journey to work.

\section{Racial/ethnic inequalities in the journey to work}

\section{$\underline{\text { Residential location factors }}$}

Research on "residential location" posits that inequalities in housing markets affect the journey-to-work. Studies have found that minorities, in particular Blacks, having lower incomes in general and facing discrimination in the housing market, tend to end up in 
poorer or more affordable neighborhoods in the suburbs, where, as found by Goddard et al. (2006), journey-to-work trips are longer both in time and distance than in traditional neighborhoods in the core.

In gentrifying cities like Portland, this means outer neighborhoods and suburbs. Because of constrained job opportunities in these neighborhoods, in addition to job market discrimination, minorities tend to have longer journeys to work. In these suburban neighborhoods minorities suffered from what Soja (2010) calls "distributional inequalities", which expresses spatial injustices in the form of lower access to basic needs, such as access to mass transit. Similarly, Harvey (2010) posits that there are "territorial injustices", referring to how the city works as a day to day machine that produces distributional inequalities. He explains how cities tend to develop concentrically around a center contributing to create and maintain geographies that proffer greater advantage to wealthier residents.

Crane (2007) also found that both male and female residents of central cities had shorter commutes than those who lived in suburban and rural areas. The residential location of many minority women (especially heads of households) in lower cost neighborhoods that offer few local employment opportunities may constrain labor force participation to a narrow range of job types (that are nearby), or employment may entail much longer commutes for these residents.

\section{Spatial mismatch}


The spatial inequality faced by racial minorities, in particular blacks, has been studied in depth by John Kain (1968), Manuel Pastor et al. (2015), and others. Soja (2010) posits that at the local scale it is not uncommon to see Blacks being displaced. He provides a good example in the form of environmental racism, which refers to the tendency for Blacks to suffer disproportionately from air and water pollution and the siting of hazardous or toxic facilities.

Kain (1968) highlighted the difficulties faced by minorities (including women) in reaching their jobs from the places they lived, which he labeled "spatial mismatch." His hypothesis assumes: (i) racial discrimination in housing and in the job market, (ii) limited public transportation between neighborhoods and job-growth areas, and (iii) that the demand for labor has shifted from central areas to suburbs (Ihlanfeldt and Sjoquist, 1998). The mismatch hypothesis set the stage for much of today's discussion about access to opportunity and the journey to work.

Cervero (1989 and 2002) posits that the growing spatial mismatch between job locations and the place of affordable housing is the cause of many urban problems. His rational was that because of the jobs-housing imbalance, a growing number of workers were forced to reside further from their workplaces. Suburbanization has influenced spatial mismatch, which seems to be the case for low-income and racial minorities in Portland.

Cervero (1989) found that suburbanization led to important changes in commuting patterns because the suburbs become, in addition to places of trip origins, places of trip destination. Although one would expect the shift of jobs location to the suburbs to reduce 
the commute distances for suburban residents, this trend, as pointed out by Cervero, actually contributed to the opposite.

Among the causes of spatial mismatch Cervero (1989 and 2002) identified (i) fiscal issues: cities tend to prefer high-tax revenues (e.g. commercial or industrial) with low services demanding; (ii) exclusionary zoning (e.g. minimum land sizes for new housing permits, restrictions for the supply of affordable housing); (iii) undersupply of housing alternatives for workers; (iv) high prices of houses and rents that priced out service workers from the local residential market; (v) the growth in dual wage earner households and career shifts. At least where couples earn comparable salaries the residential location choice is less likely to be one-sided in favor of a single spouse; (vi) choices, tastes, and preferences (Cervero, 2002 and Giuliano and Small, 1993); (vii) lack of regional land-use planning approaches; and (vii) neighbors' conflicts (NIMBY): local residents often believe that more housing (e.g. low-income housing) will result in negative environmental effects such as more traffic and crime Peng (1997).

It is argued that land-use policies (inclusionary zoning, tax-base sharing, fair sharing housing programs, regional planning, and incentive base programs) can solve some of the problems associated to job-housing imbalance (Cervero, 1989). Cervero assumed that the implementation of these policies could potentially lead to, among other policy outcomes, increase the provision of affordable housing for workers close to the suburban job centers. In contrast, Peng (1997) and Giuliano and Small (1993) found that land-use 
policies to balance jobs and housing would have a very limited impact on the overall commuting patterns in a region.

\section{Income differences in the journey-to-work}

This final section under journey-to-work examines the literature on income inequalities as they affect aspects of the work trip.

\section{$\underline{\text { Social exclusion }}$}

"Social exclusion" is is yet another means by which to assess transportation-related inequality, and is directly tied to access to transit. It is defined as the inability to participate in economic, social, and cultural life (Currie, 2011), and is influenced by personal, institutional, and societal trends. These include lack of income and employment, poor social support, and lack of access to activities due to both location and inequalities in access to transport. The term was first used by the French in the early 1970s, referring to the loss of the ability to connect with the services and facilities needed to fully participate in society (Church et al., 2000).

Social exclusion is often based on a combination of characteristics of individuals (such as low-income, lacking a car, female, older, younger, disabled, unemployed, racial minority, or single parent) and external factors (such as urban form and the public transportation system). In other words, social exclusion is produced by the interaction between land use patterns, the transportation system and individual circumstances (Currie, 2011). 
Social exclusion is often primarily the result of financial insecurity, as a consequence of which individuals become 'locked out' from the basic resources needed to secure a reasonable quality of life. Mandanipour et al. (1998) found that social exclusion embraces a broad set of poverty indicators - such as housing, education, health, and environmental factors.

"Community-level exclusion," according to Lucas (2011), occurs where there are spatial concentrations of individuals experiencing or at risk of social exclusion. This can have significant additional area-wide effects such as high levels of crime, degraded local environments and high incidences of public service delivery failure.

\section{Social exclusion and the journey to work}

The dimensions and types of social exclusion associated with transportation are interrelated (see Table 1). Lack of transport is clearly an important factor in social exclusion, since it can prevent individuals from accessing work as well as other services (e.g., education or health), and community events (Arriaga and Silva, 2012). According to Kenyon et al. (2003b) transport-related social exclusion is defined as the process by which people are prevented from participating in the economic, political and social life of the community because of reduced accessibility to opportunities, services and social networks. This is due in whole or in part to insufficient mobility in a society built around the assumption of high mobility. In addition, as posited by Clifton and Lucas (2004) public transportation is generally inadequate for meeting the mobility and accessibility needs of low-income groups. 
Lucas and Currie (2012) found that transport-related social exclusion primarily affects people who are are living below the poverty line, many of whom are too old or young to drive. As Davey (2007) found, they therefore rely on walking, public transport and lifts from others in order to participate in everyday activities. Fritze (2007) showed this to be the case especially with older adults and young mothers. Poor individuals may also be excluded from using the transit system for reasons related to its operational or physical structure. The journey to work becomes particularly difficult for those who experience social exclusion.

It is important to add that socially excluded people are likely to have low access to the formal political process as well. As a consequence, as posited by Lucas and Currie (2011) they are unlikely to be directly involved in formal transportation decision-making, and might feel alienated and disempowered by the whole public decision-making process. This in turn affects their ability to affect any changes in their situation (Hodgson and Turner, 2003).

\section{Social exclusion and transportation disadvantage}

A number of researchers have focused on the concept of "transportation disadvantage" (Currie and Stanley, 2007; Currie, 2004, 2009; Delbosc and Currie, 2011; Lucas and Currie, 2011; Clifton and Lucas, 2004; Hurni, 2005, 2006, 2007; Hine and Mitchell, 2003; Dodson et al, 2010). Analyzing transportation disadvantage and the journey to work from the social exclusion perspective allows us to consider the economic and social consequences of the absence of transport, and thus reflect on the consequences of 
individuals not being able to access jobs and participate in key life-enhancing opportunities. Indeed, as noted by Lucas and Currie (2011) there has been a move away from a traditional 'systems-based' approach to transportation provision towards a more 


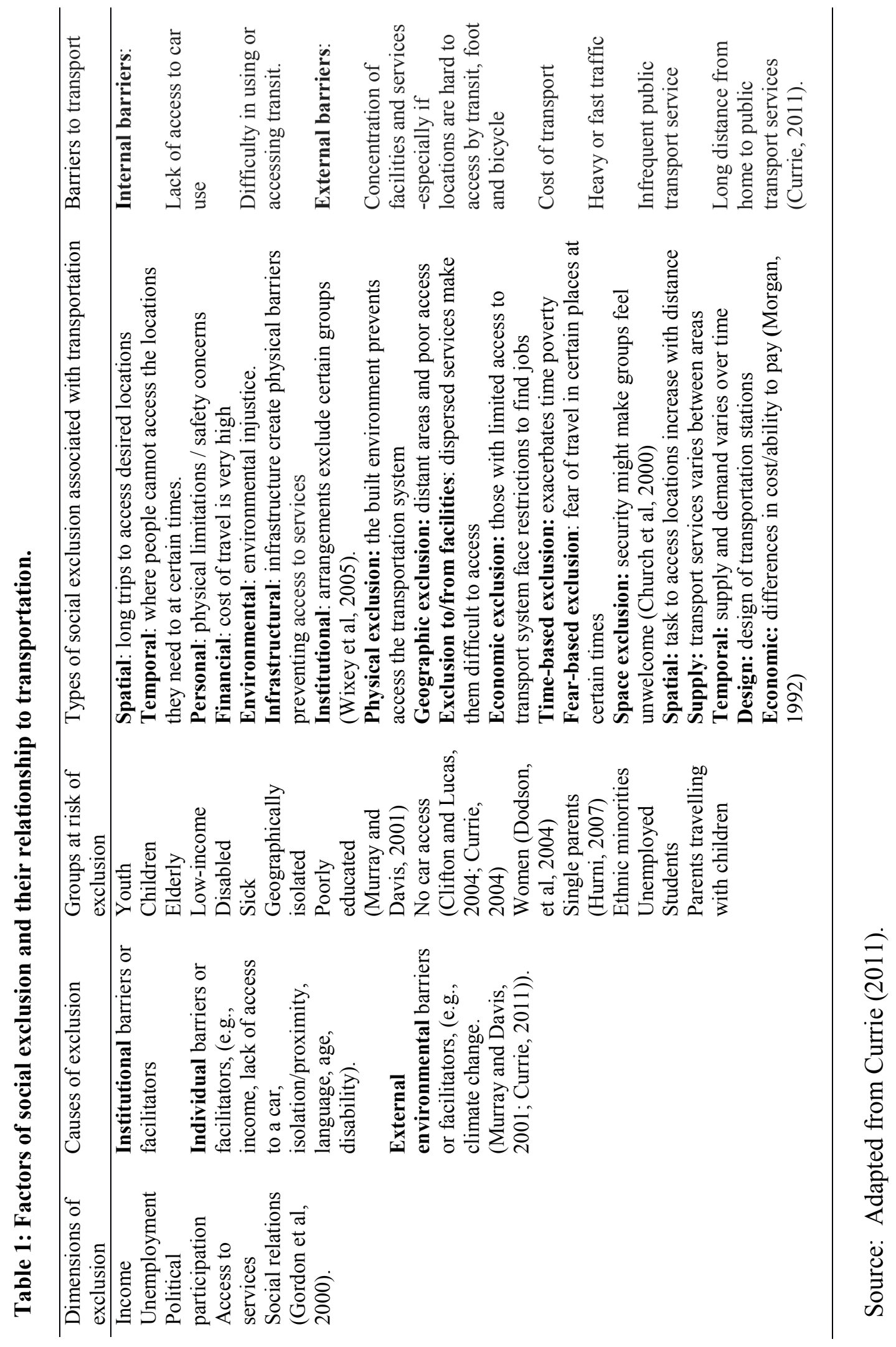


'activities-based' perspective, which asks questions about equality of opportunity and equity of outcome, and begins to raise the issue of redistributive justice.

Where the burden of mobility is too high, being transport disadvantaged can result in less travel and missed opportunities (Davey, 2007; Fritze, 2007), including jobs, thus contributing to social exclusion. Blumenberg and Hess (2003), Law (1999), and Hanson (2010) enumerate a wide variety of other means by which being transport disadvantaged can contribute to social exclusion.

According to Lucas (2012) both transport and social disadvantages can adversely affect the ability of poorer people to access opportunities. The main elements related to conditions of transport disadvantage are limited access to travel (either by public transport or car), prohibitive transit fare costs, and limited or non-existent information. The relationships between these types of disadvantage show that a lack of assets can be worsened by poor transport provision and increasing barriers to access activities, thus leading to processes of social exclusion. Conditions of social vulnerability force people in poverty to live in less attractive areas, with limited access to jobs and poor transport provision.

Individuals who lack access to a car are often referred to as "captive riders" (Rutherford et al, 1988) because it is assumed they will continue using public transit despite declines in service. Captive riders are often forced to limit their travel, especially to more distant jobs and other destinations, and to live in closer-in urban neighborhoods (Mollenkopf et al., 2005; Lau, 2006), though often they cannot afford it. 
In the U.S. the number of households without cars declined from $20 \%$ in 1970 to only 9.2\% in 2012. That figure, however, is higher for Portland, where the percentage of carless households in 2012 was 15.3\%, of whom 65.4\% were low-income (Sivak, 2014). Although low-income households have increased their access to cars, they are still overrepresented among car-less households.

According to Tomer (2013), 60\% of zero-vehicle households in the top 100 metropolitan areas in the U.S. have incomes below $80 \%$ of the median income for their metropolitan area. Giuliano (2005) noticed that $22 \%$ of poor households in the U.S. have no drivers (a person having a valid driver's license), compared to $5 \%$ of all households. Similarly, $30 \%$ of poor households have no private vehicle, compared to only $7.7 \%$ of all households.

\subsection{Explaining inequalities in household-serving trips}

This section explores the research on gendered travel behavior and gender socialization, which is used in later chapters to explain differences in the number, duration, and distance of household-serving trips among family types. Gender inequalities in the division of household work not only affect the journey-to-work, but also lead to gender differences in household-serving trips.

Explanations of gender-related travel differences often rely on feminist concepts such as 'gender roles', which illuminated women's experiences, particularly constraints faced by mothers of young children and housewives (Tivers, 1985). In this section, theories and concepts around family structure and gendered travel behavior, gender socialization, and 
the design of the built environment are reviewed with respect to gender differences in household-serving trips.

\section{Family structure and gendered travel behavior}

Family structure is relevant to understanding travel behavior because the number of adults and children in the household might reveal trip-making needs (Chu et al, 2000). The most common family structure categories used by transportation researchers are: (i) single adults living alone; (ii) single parents living with children, but no other adults; (iii) married couples living together with no others; and (iv) married couples living together with children (Rosenbloom, 2006; Taylor et al, 2015; Crane, 2007, 2009).

Rosenbloom (2006) found gender differences in travel in every family structure category, with women making a greater percentage of their trips for shopping and to accommodate other people than comparable men in similar categories. Also, women in all household types have shorter average commutes than their male counterparts (Crane, 2007). Table 2 summarizes the findings of empirical studies of gendered travel behavior associated with family structure.

Table 2: Findings of empirical studies of gendered travel behavior by family structure Gender differences in travel behavior

- Women make a greater percentage of trips for shopping and to accommodate other people than comparable men in similar family categories and are more likely to "chain trips" together particularly women with children (McGuking \& Nakamoto, 2005; DeLuca, 2011; Taylor et al, 2015; Rosenbloom, 2006; Crane, 2007). 
- Women in all household types have shorter average commutes than their male counterparts (Crane, 2007)

- Women with young children owned more cars, traveled longer distances, made more trip-chaining, and carpooled to/from work with household members more frequently than women without children Goddard et al, (2006).

- Married women living with a spouse have the longest commute among women

- Married men living with wives and children have the longest commute among men.

- Married men have longer commutes than single men and married women have shorter trips than single women (Crane, 2009).

- Single parents make more trips, trip-link more often than married parents of either sex

- Single mothers make more trips solely to chauffeur their children, make more of their total trips to serve passengers, make a greater percentage of their trips for shopping and personal business, and make lower trips for social purposes than single fathers (Rosenbloom, 2006).

- Women make more trips per day than men, though shorter (time and distance) (Rosenbloom, 2006; Crane, 2009).

- Women are more likely to bring a vehicle to work to take their children to daycare or school (Taylor et al, 2015).

- Single women with no children made more child/house-serving trips as similar men (Taylor et al, 2015).

\section{Gender socialization}

Couples typically divide up the housework based on gender ideologies, which are beliefs about the appropriate roles and behaviors of men and women. This approach sees "gender roles" as the primary determinant of the division of work, assigning females to "women's work" and males to "men's work". Couples who hold more egalitarian attitudes tend to have a more balanced division of household labor (Davis, et al., 2007, 2009); although research shows that even well-educated women who work with unemployed or under- 
employed male partners do more house-work than their partners. Taylor et al., (2015) found that the role and influence of gender ideology is remarkably strong in explaining why women (even single childless women) made more child-serving and grocery shopping trips as men.

These finding are important with respect to this study because they show the relationship between gendered activity patterns and travel behavior.

\section{Role of the built environment}

Law (1999) posits that gendered travel is influenced by both gendered norms of household responsibilities (which are overlaid on temporal rhythms of childcare and domestic work) and the built environment (e.g., spatial patterns of segregated land-uses, inflexible service hours, and minimal public transport), which generate time-space constraints (due for example to safety issues) that restrict women's mobility, especially mothers.

Living in dense, accessible, compact and mixed land use communities, as posited by Crane (2007), Rosenbloom (2006), Handy (2004), and Kwan (1999), would benefit women with children, because a built environment designed in a way that the necessary destinations (e.g., schools, stores, day care) are close to home can make it easier for women to conduct their everyday lives. The rationale is that proximity to destinations would make travel easier for women by reducing the distance to take care of their household responsibilities. Further, Rosenbloom (2006) posits that if communities were designed so that walking and 
transit were safe and adequate, dependent children could get to where they need to go by themselves, reducing the burden on women to chauffeur them. The reduced need for driving would save women time and money and increase their flexibility.

The next chapter lays out the research design for this dissertation. It presents the research questions, hypotheses, and theories that are drawn on to support the hypotheses. It also introduces the data and variables used in the study and describes the methods of analysis. 


\section{Chapter 3. Research Design: Questions Hypotheses, Data and Methodology}

This chapter presents the research questions and hypotheses that form the core of this study, followed by a discussion of the data and variables used in the study. A shortcoming of the data sets will be highlighted. The chapter ends with an overview of the methods of analysis applied to the data sets.

\subsection{Research questions and hypotheses}

As outlined in the introduction, this dissertation seeks to understand how socially and economical disadvantaged groups in Portland have been affected by neoliberal transit policies and decisions. Research questions are organized around inequalities in three key areas:
1) Access to public transit
2) Journey-to work (by race/ethnicity, class and gender)
3) Household-serving" trips (by gender among family types)

\section{Inequalities in access to public transit}

The first research question, looking at access to transit over two decades in metropolitan Portland, asks: What has been the effect of neoliberalism on access to public transit?

Two hypotheses are tested in answering this question:

Hypothesis 1: Impoverished-dependent riders (i.e., transit riders who are too poor to own a car) will become more "transportation-disadvantaged" over time than choice-dependent riders - i.e., they will have fewer transit routes available, lower frequency of service, more distant transit stations, and longer and lengthier trips. 
This hypothesis is consistent with the outcome expected from the "urban growth machine" thesis (discussed in the introduction and literature review). In the competition to grow the city, elites focus on improving the core where returns and profits are high and they can benefit from the resulting rise in rents. However, these rising rents cause lowincome individuals to seek housing elsewhere, which is most often in a transit-poor, outer neighborhood or suburb. And thus it happens in a growing city like Portland, with an active growth machine focused on the core, that impoverished-dependent riders become more transportation-disadvantaged over time as they end up living in transit-poor suburbs.

Hypothesis 2: Low-income individuals will increasingly be forced to own a car ("forced car ownership") since an increasing share will be living in places with lower access to transit.

Fred Block's theory of the capitalist state leads one to predict such an outcome. To maintain a healthy business climate, government bureaucrats (including transportation planners), agency heads, and other "state managers" are reluctant to extend the state's role because it would increase the tax burden on businesses. They will be reluctant to expand bus service within low-income communities on the periphery of the city, as this would increase the state's role as well as the tax burden on businesses, creating a less friendly business climate. Since a growing share of low-income individuals in Portland are now living in these transit-poor neighborhoods on the outskirts of the city, more will be forced to purchase a car in order to get around ("forced car-ownership"). 
Both of these hypotheses are also the expected result of neoliberal policies, the workings of which are discussed in detail in the introduction and literature review, with the example of Chicago.

\section{Inequality in the Journey-to work}

Understanding differences in the journey-to-work - by race/ethnicity as well as income can offer important insights into inequality around job accessibility. This study therefore explores the research question: How do gender, race/ethnicity, and income inequality affect the journey-to-work in Portland? Three hypotheses are tested:

Hypothesis 3 (Gender): Due to unequal social relations in the household and inequalities in the job market, the journey-to-work will be shorter for women than for men.

Research and theories on "social relations in the household" support this hypothesis, explaining in detail how women must coordinate dual roles as housewives and wage earners, and how shorter work trips enable them to coordinate their many activities (MacDonald, 1999). Other research supporting Hypothesis 3 focuses on inequalities in the job market and finds that women, who tend to hold low-paid, part-time jobs in the service sectors, earn less, and work shorter hours, are more likely to seek employment closer to home to reduce time spent travelling (MacDonald, 1999; Madden, 1981). 
Hypothesis 4 (Race/Ethnicity): Given that minorities tend to live in lower-cost isolated neighborhoods with few local employment opportunities, the journey-towork will be longer for minorities than anyone else.

This hypothesis is consistent with "residential location" research, which has found that minorities, in particular Blacks - who tend to live in lower-cost isolated neighborhoods with few local employment opportunities nearby - must seek and take jobs farther from their homes than whites, in part due to scarcity of employment opportunities near where they live.

Hypothesis 5 (Class): The journey-to-work distance will be shorter for lowincome individuals than for everyone else, since they tend to seek and obtain lowpaying jobs close to home (typically a low-income neighborhood).

This hypothesis draws on research on the relationship between journey-to-work and class, which has found that low-income individuals in general travel shorter distances to work due to lower levels of mobility than those with higher incomes. Much of this research was described in the literature review. Lucas (2012), for example, shows how such lack of mobility is associated with social exclusion, since the poor cannot reach opportunities due to lack of a car or sometimes even the means to afford transit. In their research on residential choice, Doyle et al. (2000) found that low income individuals are often restricted to low-income neighborhoods (which have a large share of low-paying jobs). This seems to hold true in metropolitan Portland with the increase in low-income individuals living in low-income neighborhoods in the outskirts of the city. This furthers their social exclusion. 


\section{Inequalities in "household-serving” trips}

A third focus of this dissertation is on inequality in household-serving trips by gender. The research question here is: How do household-serving trips vary by gender in Portland? Just one hypothesis is tested here:

Hypothesis 6: Women in general - whether single, married, with children, or childless - will make more household-serving trips than men.

This is the expected outcome of the body of theories around "gender socialization," which posit that gender roles are the primary determinants of the division of work. Women are assigned to "women's work" and men to "men's work." The consequence of such a strong division of roles is that women in general make more child-serving and grocery shopping trips (i.e., "women’s work") than men.

\subsection{Data Sources}

The following data sources were used for this study:

- The 1994 Portland Housing Activity and Travel Survey (POTAS)

- The 2011 Oregon Travel and Activity Survey (OTAS)

- U.S. Census Bureau Data

- Regional Land Information System (RLIS)

Each of these data sources is described in the sections below.

1994 Portland Household Activity and Travel Survey (POTAS) 
The 1994 Portland Household Activity and Travel Survey (POTAS) was conducted by the Portland Metropolitan Services District. Of the 7,090 households recruited for the survey, 4,451 households (a total of 9,471 individuals) returned completed and usable surveys. Each household was assigned two consecutive travel days to record in a diary the activities for all household members. The travel days assigned to households were varied to capture data representing the seven days of the week, and to explore individuals' travel behavior and activity patterns.

Data was collected at the household, person, activity/travel, and vehicle levels. A random probability sample of telephone numbers was purchased, from which households were recruited in each geographic strata (as a consequence it might be that low-income households were under-represented). Data collection for the survey included the following steps: (1) recruitment of household by telephone; (2) mailing survey packets to participating households; (3) reminder calls to participating households on the day before their designated travel days; and (4) retrieval of data via telephone interviews after the second designated travel day.

The analysis was restricted to individuals older than 18 years from three counties in the Portland metro area (Multnomah, Clackamas, and Washington), resulting in a sample of 2,981 households and 6,642 individuals. To make the data comparable to that of the OTAS (2011), the 1,073 households from Columbia and Yamhill Counties were excluded. Saturdays and Sundays were omitted from the analysis. In addition, one of the two days for which data was recorded was randomly selected. To facilitate the analysis, 
the files were reorganized in such a way that the household, travel and activity information were combined into the person file.

\section{Oregon Travel and Activity Survey (OTAS)}

The OTAS (2011) was conducted between 2009 and 2011 among 18,000 households by the Oregon Modelling Steering Committee to explore individuals' travel behavior and activity patterns. It includes household, individual, vehicle, activity, and trip information. Questions were asked on a designated travel day (24 hours: starting at 3:00 a.m.) and participants were asked to keep a diary of their travel and activities. Participants in the survey were taken from a list of household addresses randomly selected to ensure participation from across Oregon. Households with listed phone numbers were contacted by phone (individuals older than 16 were interviewed). Those households without a listed phone were contacted by mail. As with the POTAS survey, the analysis was restricted to individuals older than 18 years from 4,800 households in three counties in the Portland metro area (Multnomah, Clackamas, and Washington) resulting in a sample of 8,818 individuals. 1,650 households from Clark County in the adjacent state of Washington were excluded.

\section{U.S. Census Bureau Data}

U.S. Census Bureau data was analyzed via Social Explorer. Specific datasets include the 2000 Census, 2010 Census, and 2009-2013 American Community Survey (ACS).

\section{Regional Land Information System (RLIS)}


Data from Portland Metro's Regional Land Information System (RLIS) was used to get data on the MAX light rail and bus network, including frequencies and stop locations, for the periods of 2011 and 1997 . The 1997 GIS file, the earliest available, was provided by TriMet, the regional transportation authority. While 1997 data doesn't correlate exactly with the 1994 survey data, it is close enough for the purposes of this analysis.

\subsection{Variables and methods of analysis}

Both the variables and methods of analysis used in the study are organized around the three key inequality issues examined in this study:

1) Changes in access to public transit

2) Differences in journey-to work (by race, income and gender)

3) Differences in "household-serving" trips (by gender among family types)

\section{Changes in access to public transit}

\section{Dependent Variables}

The dependent variables (see Table 3) used in the study were created based on the OTAS (2011), the POTAS (1994) surveys, and the Regional Land Information System (RLIS). Variables were of two types: travel behavior variables and access-to-public transit variables.

- Travel behavior variables included transport mode, number of trips, trip distance, travel time, and other variables.

- Access-to-public transit variables included distance to public transit stops, number of unique transit service lines with stops within $500 \mathrm{~m}$ of respondents' homes 
(MAX, Streetcar (STC) and buses), and frequent bus service (only available for the OTAS 2011 since it was not available in 1994). Although the consideration of frequency and diversity of routes strengthened the measures of access to public transit, to go beyond distance to transit from respondents' homes, results should be interpreted with a caveat because it is difficult to conclude whether the transit service connects with the right destination at the desired time. There are other aspects to consider as well, such as reliability, safety, quality, cost of travel (fares and time), or effects of trip-chaining (Clifton and Lucas, 2004; Kwan, 1999; Currie 2011).

Table 3: Dependent variables in the study

\begin{tabular}{|c|c|c|}
\hline Dependent Variables & Description and Measurement & Source \\
\hline Transport mode & $\begin{array}{l}\text { Public transit (Max light rail, bus), car, bicycling and } \\
\text { walking. }\end{array}$ & $\begin{array}{l}\text { OTAS } 2011 \& \\
\text { POTAS } 1994\end{array}$ \\
\hline $\begin{array}{l}\text { Number of transit } \\
\text { transfers }\end{array}$ & Share of riders making transfer. & $\begin{array}{l}\text { OTAS } 2011 \& \\
\text { POTAS } 1994\end{array}$ \\
\hline Number of trips & Average number of daily trips & $\begin{array}{l}\text { OTAS } 2011 \& \\
\text { POTAS } 1994\end{array}$ \\
\hline Day trip distance & Average distance travelled per day & OTAS $2011 \&$ \\
\hline Distance to work & Average distance from home to work location & POTAS 1994 \\
\hline Travel time & Average travel time & OTAS 2011 \\
\hline $\begin{array}{l}\text { Distance to nearest } \\
\text { transit station }\end{array}$ & $\begin{array}{l}\text { Average distance to the nearest bus or MAX light rail } \\
\text { stop, from each of the respondents' households }\end{array}$ & $\begin{array}{l}\text { RLIS } 2011 \& \\
1997\end{array}$ \\
\hline $\begin{array}{l}\text { Unique transit route } \\
\text { choices }\end{array}$ & $\begin{array}{l}\text { Average number of unique transit routes within a } 500 \\
\text { meters radius from each of the respondents' households }\end{array}$ & $\begin{array}{l}\text { OTAS } 2011 \& \\
\text { POTAS } 1994\end{array}$ \\
\hline $\begin{array}{l}\text { Unique frequent route } \\
\text { choices }\end{array}$ & $\begin{array}{l}\text { Average number of unique frequent transit routes within } \\
\text { a } 500 \text { meters radius from respondents' households }\end{array}$ & $\begin{array}{l}\text { RLIS } 2011 \& \\
1997 \\
\text { OTAS } 2011 \& \\
\text { POTAS } 1994\end{array}$ \\
\hline
\end{tabular}

Sources: OTAS, 2011; POTAS, 1994; RLIS, 1997 and 2011.

The number of unique transit service lines measures the availability of different route choices within a 500-meter radius from each respondent's household. The number of unique "frequent service" lines measures the availability of frequent service routes within a 500-meter radius from each respondent's household. See Table 3 for a full list and description of dependent variables.

\section{Independent Variables}


The independent variables were created using data from the OTAS (2011) and POTAS (1997) surveys (see Table 4).

Table 4: Independent variables in the study

\begin{tabular}{|c|c|c|}
\hline Independent Variables & Description & Source \& measurement \\
\hline \multirow[t]{3}{*}{ Disabled Dependent } & No vehicle in the household (HH) & OTAS $2011(\mathrm{n}=115)$ \\
\hline & Adults & POTAS $1994(n=41)$ \\
\hline & Physical disability & \\
\hline \multirow[t]{3}{*}{ Impoverished Dependent } & No vehicle in the $\mathrm{HH}$ & OTAS $2011(\mathrm{n}=127)$ \\
\hline & Adults & POTAS $1994(n=72)$ \\
\hline & At or below $150 \%$ federal poverty line* & \\
\hline \multirow[t]{4}{*}{ Choice Dependent } & No vehicle in the $\mathrm{HH}$ & OTAS $2011(n=150)$ \\
\hline & No driver license & POTAS $1994(n=196)$ \\
\hline & Adults & \\
\hline & Above poverty & \\
\hline \multirow[t]{4}{*}{ Disabled Disadvantaged } & Vehicle in the $\mathrm{HH}$ & OTAS $2011(\mathrm{n}=144)$ \\
\hline & No driver license & POTAS $1994(n=43)$ \\
\hline & Adults & \\
\hline & Physical disability & \\
\hline \multirow{4}{*}{ Impoverished Disadvantaged } & Vehicle in the $\mathrm{HH}$ & OTAS $2011(n=68)$ \\
\hline & No driver license & POTAS $1994(n=27)$ \\
\hline & Adults & \\
\hline & At or below $150 \%$ federal poverty line & \\
\hline \multirow{4}{*}{ Choice Disadvantaged } & Vehicle in the $\mathrm{HH}$ & OTAS $2011(\mathrm{n}=175)$ \\
\hline & No driver license & POTAS $1994(\mathrm{n}=172)$ \\
\hline & Adults & \\
\hline & Above poverty & \\
\hline \multirow{4}{*}{ Disabled Mobile } & Vehicle in the $\mathrm{HH}$ & OTAS $2011(\mathrm{n}=433)$ \\
\hline & Driver license & POTAS $1994(n=96)$ \\
\hline & Adults & \\
\hline & Physical disability & \\
\hline \multirow[t]{4}{*}{ Impoverished Mobile } & Vehicle in the $\mathrm{HH}$ & OTAS $2011(\mathrm{n}=617)$ \\
\hline & Driver license & POTAS $1994(n=384)$ \\
\hline & Adults & \\
\hline & At or below $150 \%$ federal poverty line & \\
\hline \multirow[t]{4}{*}{ Choice Mobile } & Vehicle in the $\mathrm{HH}$ & OTAS $2011(n=6,970)$ \\
\hline & Driver license & POTAS $1994(n=6,642)$ \\
\hline & Adults & \\
\hline & Above poverty & \\
\hline
\end{tabular}

Sources: OTAS (2011) and POTAS (1997) *Poverty guidelines are a federal poverty measure issue each year by the Department of Health and Human Services (HHS)

The nine "mobility groups" in this study (see Figure 1 and Table 5) were used as independent variables. To define these mobility groups, survey respondents were first 
separated by vehicle ownership: those who lived in households with at least one vehicle, and those who did not. Those owning vehicles were then classified by possession or lack of possession of a valid driver's license. The next step was to sort respondents based on possible explanations for their dependence - i.e., disadvantage or disability.

They were sorted by whether or not they had a disability that limited the ability to travel (i.e., has such disability vs. does not have) and if they had no such disability, they were

Table 5: Mobility group characteristics

\begin{tabular}{|c|c|c|}
\hline $\begin{array}{l}\text { (i) Disabled Dependent: } \\
\text { - } \quad \text { No vehicle in the } \\
\text { Household (HH) } \\
\text { - } \quad \text { Adults } \\
\text { - } \quad \text { Physical disability } \\
\text { (ii) Impoverished Dependent: } \\
\text { - No vehicle in the HH } \\
\text { - } \quad \text { Adults } \\
\text { - } \\
\text { At or below } 150 \% \\
\text { (iii) Choice Dependent: } \\
\text { - } \quad \text { No vehicle in the HH } \\
\text { - } \text { Adults } \\
\text { - } \text { Above Poverty }\end{array}$ & $\begin{array}{l}\text { (iv) Disabled Disadvantaged: } \\
\text { - } \quad \text { Vehicle in the HH } \\
\text { - } \quad \text { No driver license } \\
\text { - } \quad \text { Adults } \\
\text { - } \quad \text { Physical disability } \\
\text { (v) Impoverished Disadvantaged: } \\
\text { - } \quad \text { Vehicle in the HH } \\
\text { - } \quad \text { No driver license } \\
\text { - } \quad \text { Adults } \\
\text { - } \quad \text { At or below } 150 \% \text { federal } \\
\text { poverty line } \\
\text { (vi) Choice Disadvantaged: } \\
\text { - } \quad \text { Vehicle in the HH } \\
\text { - No driver license } \\
\text { - } \quad \text { Adults } \\
\text { - Above poverty }\end{array}$ & $\begin{array}{l}\text { (vii) Disabled Mobile: } \\
\text { - } \quad \text { Vehicle in the HH } \\
\text { - } \quad \text { Driver license } \\
\text { - } \text { Adult } \\
\text { - } \text { Physical disability } \\
\text { (viii) Impoverished Mobile: } \\
\text { - Vehicle in the HH } \\
\text { - } \quad \text { Driver license } \\
\text { - Adult } \\
\text { - At or below } 150 \% \\
\text { (ix) Choice Mobile: } \\
\text { - Vehicle in the HH } \\
\text { - Driver license } \\
\text { - Adult } \\
\text { - Above poverty }\end{array}$ \\
\hline
\end{tabular}

Source: Based on Dill et al. (2014).

sorted by income level to identify whether they were disadvantaged (non-disabled at or below $150 \%$ of federal poverty level [disadvantaged] vs. non-disabled and above $150 \%$ of federal poverty level). The nine mobility groups also distinguished between car drivers and public transit users, and both (drivers and transit users) were separated into "choice" or "non-choice". 


\section{Mobility Groups' Conceptualization Flow Chart}

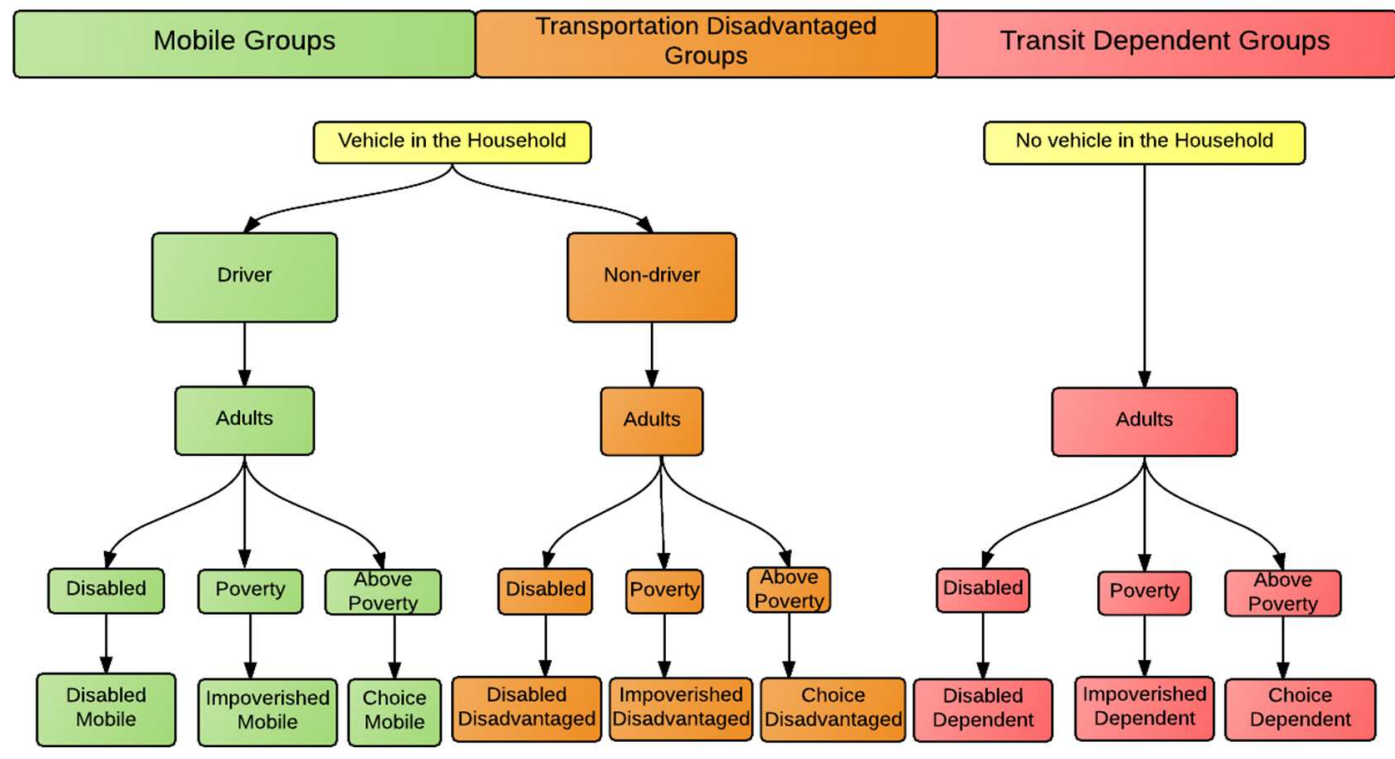

Figure 1. Mobility groups' conceptualization chart

"Choice" individuals are those with enough income to own a car but who opt to use transit and not own a car ("choice riders"), or those with enough income to own a car who choose to drive a car ("choice drivers"). "Non-choice" individuals are those who rely on public transit because they cannot afford to own a car, or individuals at or below poverty who drive a car (forced car owners). In addition, socio-demographic variables were used as controllers (e.g., household size, age, race, etc.).

\section{Income Categories}

Three income categories were defined for this study: low-income, middle-income and high-income, according to the 2013 population survey annual social and economic supplement (Renwick et al., 2014). The measure of poverty used in the study to define 
"low-income" is $150 \%$ of the federal poverty guidelines for the years 1993 and 2010. These guidelines are issued each year by the U.S. Department of Health and Human Services (HHS). The reason for using $150 \%$ was to increase the sample size of socially disadvantaged groups.

\section{Methods of Analysis for Assessing Access to Transit}

ArcMAP 10.1 was used to develop the accessibility to public transit measures. Access distance to public transit stops was calculated based on the mean distance from each household address to the nearest bus stop or MAX light rail station. First, the 'Near' analysis tool was used to measure the nearest distance to public transit stops (MAX, Streetcar (STC), buses) from each respondent's household address. (Respondents from OTAS (2011) and the POTAS (1994) surveys were asked to provide their home address). Second the 'Buffer' analysis tool was used to create a 500-meter buffer around each of the respondent's households and a 'Spatial Join' analysis tool to identify: (i) the number of unique bus, STC, and MAX light rail transit routes within the buffer area; and (ii) the number of unique frequent bus, STC, and MAX light rail transit routes. These two additional variables were created due to the limitations of measuring accessibility to public transit only through distance to transit stations (Clifton and Lucas, 2004; Kwan, 1999). These additional variables strengthened the measures of access to public transit by households. They also provided information about the availability of different route choices, and thus potential access to a diverse array of destinations. Together, these 
variables served as an indicator of transit access from home. These measures were calculated using data from RLIS 2013 and 1997 and the OTAS (2011) and POTAS (1994) surveys.

Statistical analysis of variance (ANOVA) was used to compare the mean differences among mobility groups on the dependent variables. Also, a multiple regression analysis with analysis of interaction was conducted to assess the relationships between mobility groups (independent variables) and access to transit and travel behavior variables (dependent variables) in the two periods of time.

\section{Differences in journey-to work by race, class and gender}

\section{Dependent Variables}

Table 6 shows the dependent variables used in this study.

Table 6: Dependent variables for the journey-to-work analysis

\begin{tabular}{lll}
\hline Dependent Variables & Description and Measurement & Source \\
\hline Transport mode to work & Public transit: Max light rail and bus, car, bicycling, and & POTAS 1994 \\
& walking & 2011 OTAS \\
Trip distance to work & Average linear distance from home to work & POTAS 1994 \\
& & 2011 OTAS \\
Travel time to work & Average travel time from home to work and vice-versa & POTAS 1994 \\
& & 2011 OTAS \\
\hline
\end{tabular}

Sources: POTAS (1994); OTAS (2011)

\section{Independent Variables}

The independent variables (see Table 7) were created using data from the OTAS (2011) and POTAS (1994) surveys. Due to a lack of similar variables between the two analyzed surveys, such as education level and occupation, for comparative reasons the social class 
variables were defined based on income according to the 2013 population survey annual social and economic supplement (Renwick et al., 2014).

For the creation of the class variables, survey respondents were first separated by employment status (since the focus of this study is the journey-to-work): the two statuses were those employed (either part-time or full-time), and those who were not employed, and thus were not considered in the analysis. The next step was to categorize employed respondents into social classes, based on their annual income. As mentioned earlier, the measure of poverty used here to define the "low-income class" was $150 \%$ of the federal poverty guidelines for the years 1993 and 2010. These guidelines are issued each year by the U.S. Department of Health and Human Services (HHS). The reason for using 150\% was to increase the sample size of socially disadvantaged groups; otherwise the sample was too small.

Table 7: Independent variables for the journey-to-work analysis

\begin{tabular}{lll}
\hline Independent Variables & Description and Measurement & Source \\
\hline $\begin{array}{l}\text { Individual economic \& } \\
\text { demographic attributes } \\
\text { Gender }\end{array}$ & Male and female & 2011, OTAS \\
& & 1994, POTAS \\
Working status & Part-time or full-time workers & 2011, OTAS \\
& & 1994, POTAS \\
Number of jobs & Number of jobs & 2011, OTAS \\
& & 1994, POTAS \\
Housing tenure & Owned/mortgaged, rented & 2011, OTAS \\
& & 1994, POTAS \\
Size of household & Number of People in Household & 2011, OTAS \\
& & 1994, POTAS \\
Poverty & Poverty150\% federal poverty line & 2011, OTAS \\
The number of cars & Number of vehicles in the household & 1994, POTAS \\
in the household. & & 2011, OTAS \\
County of residence & Multnomah, Clackamas, Washington & 1994, POTAS \\
Race/ethnicity & White, Black, Latino, & 2011, OTAS \\
Low-income & & 1994, POTAS
\end{tabular}


Middle-income

High-income
Between 25 th- 75 th percentile $(1994=\$ 30,000-\$ 59,000$, $2011=\$ 50,000-\$ 99,000)$.

25 th percentile $(1994=\$ 60,000$ and higher; $2011=\$ 99,000$ and higher)
2011, OTAS

1994, POTAS

2011, OTAS

1994, POTAS

Sources: POTAS, (1994); OTAS, (2011)

\section{Methods of analysis for assessing differences in journey-to-work}

The journey-to-work variable considers trips from "home" to a fixed "work" location and also from "work to home". Statistical analysis of variance (ANOVA) was used to compare the mean differences among racial groups and social class categories on the journey-to-work (travel time and travel distance). Multiple regression with analysis of interaction was used to analyze the effects of gender combined with class and race on the journey-to-work - in other words, to see if the effects of class and race on distance to work and travel time depended on gender.

\section{Differences in "household-serving" trips by gender among family types}

\section{Dependent variables}

Table 8 shows the dependent variables for travel behavior used in the study.

Table 8: Dependent variables for the household-serving trips analysis

\begin{tabular}{ll}
\hline $\begin{array}{l}\text { Dependent } \\
\text { Variables }\end{array}$ & Description and Measurement \\
\hline $\begin{array}{l}\text { Travel mode } \\
\text { Number of trips }\end{array}$ & $\begin{array}{l}\text { Public transit: Max light rail and bus, car, bicycling, and walking } \\
\text { Average number of trips by purpose (house-serving, work-related, and } \\
\text { discretionary) }\end{array}$ \\
$\begin{array}{ll}\text { Trip distance } \\
\text { Aravel time }\end{array}$ & $\begin{array}{l}\text { Average trip distance } \\
\text { Trip purpose categories }\end{array}$ \\
\hline Work-related & $\begin{array}{l}\text { Trips from "home to a work fixed location" and the other way around as } \\
\text { well as "work related" trips (e.g. attending a meeting). This category }\end{array}$ \\
& $\begin{array}{l}\text { includes "stops" along the way for the following purposes: i) change mode } \\
\text { of transportation, and ii) "other" (i.e. trips to school). }\end{array}$ \\
\hline
\end{tabular}


Household- $\quad$ This category includes: i) drop off/pick up passengers from car, routine serving trips shopping (e.g. groceries), major shopping (e.g. electronics or household repairs) and household errands (e.g. going to the dry cleaning). These trips were made 1) on the way to work, 2) home-based trips (directly from home), and include 3 ) change mode of transportation, and 4) "other" (trips to school, personal business, etc.). These Household-maintenance trips serve to operationalize 'gendered travel', following Taylor (2015).

Discretionary This category includes "stops" along the way for the following purposes: i) eat meal outside home, civic/religious activities, outdoor and indoor recreation/entertainment, visits friends and relatives, athletic events, rest and relaxation, hobbies, amusements (at home and outside home), formal and casual entertaining, and culture; ii) change mode of transportation; and iii) "other" (trips to school, personal business, etc.).

Sources: Sources: POTAS, (1994); OTAS, (2011); RLIS, (1997 and 2012).

Following Taylor (2015) house-serving trips will serve to operationalize 'gendered travel'. The trip purpose categories used by Golob and McNally (1996) were adapted to conduct the analysis. The independent variables used in the study are shown in Table 9.

Both type of variables were created using data from the OTAS (2011) and POTAS (1994) surveys. A typology of four family categories was developed: i) adults living alone, ii) adult couples without children, iii) couples with children and iv) single parents, leading to a final sample size of 12,282 individuals.

\section{Independent Variables}

Table 9 shows the independent variables used in the study.

Table 9: Independent variables for the household-serving trips analysis

\begin{tabular}{ll}
\hline Independent Variables & Description and Measurement \\
\hline $\begin{array}{l}\text { Socio-economic attributes } \\
\text { Employment }\end{array}$ & $\begin{array}{l}\text { Male and female } \\
\text { Number of employed individuals }\end{array}$ \\
$\begin{array}{l}\text { Number of jobs } \\
\text { Nousing tenure }\end{array}$ & Owned/mortgaged, rented \\
Size of household & Number of people in household \\
Lower-income & Those below the $150 \%$ federal poverty line
\end{tabular}


Number of automobiles in the household.

County of residence

Race/ethnicity

Family Type

Individuals living alone

Adult individuals living alone

Couples with no children

Couples with children

Single parents
Number of vehicles in the household

Multnomah, Clackamas, Washington

White, Black, Latino,

Adult couples (partners/married) with no children and no more adults living in the household Adult couples (partners/married) with children and no more adults living in the household Adult single parents (male and female) living with no more adults in the household

Sources: POTAS, (1994); OTAS, (2011).

\section{Methods of Analysis}

The main method of analysis used in examining differences in household-serving trips was regression with analysis of interaction. The interaction effect analyzes the effect of two independent variables on a dependent variable. This approach allows one to identify any combined effects of two independent variables. If there is a significant interaction, it indicates that, overall, the effect of one independent variable depends on the level of the other independent variable.

\section{A systemic problem: minority under-representation in the travel surveys}

During the course of the research, it was discovered that the travel activity surveys in both periods of time under-represented Black and Latino populations. In some cases there were not enough responses to be able to make statistically significant conclusions about specific questions. Karner and Niemeier (2013) assert that under-representation of minorities in data used for modeling illustrates deficiencies in the transportation planning process. Flawed travel demand models used to assess the effects of plans on protected 
populations end up limiting the mitigation of adverse impacts on those populations (i.e. low-income people, people of color, and transit-dependent individuals). They further found that policy recommendations generally lack specificity and are rarely enforceable and thus transportation outcomes still show disparities on the basis of race and class. Given the problems with survey data, they recommend that transportation agencies shift from traditional methodological approaches (such as aggregate, four-step, travel-demand models) to more advanced methods, and define a priori target populations based on demographic thresholds for areal units rather than on the basis of exposure, if they really want to identify and mitigate racially disparities. They concluded that a meaningful transportation equity analysis would necessarily include an assessment of both current and near-term conditions and provide racially specific outcomes, while seeking to mitigate inequities through programming decisions.

In the next chapter, the hypotheses put forth in this study are tested using the statistical analyses described above. Each hypothesis draws on one or more relevant theories as discussed in depth in the literature review. 


\section{Chapter 4. Analysis}

This chapter presents an analysis of the data to test a set of research hypotheses around the three essential transportation inequality issues: 1) Access to public transit; 2) Journeyto work; and 3) "Household-serving" trips.

\subsection{Analyzing access to public transit}

The analysis in this section is based on the following research question and hypotheses:

Research Question: What has been the effect of neoliberalism on access to public transit?

Hypothesis 1: Impoverished-dependent riders (i.e., transit riders who are too poor to own a car) will become more "transportation-disadvantaged" over time than choice-dependent riders - i.e., they will have fewer transit routes available, lower frequency of service, more distant transit stations, and longer and lengthier trips.

Hypothesis 2: Low-income individuals will increasingly be forced to own a car ("forced car ownership") since an increasing share will be living in places with lower access to transit.

To answer this question and test the hypotheses, changes in access to public transportation between 1994 and 2011 are assessed for two of the nine mobility groups: “choice dependent" (choice riders) and "impoverished-dependent" (transit-dependent) to see whether transit-dependent riders (who are necessarily low income and do not own a car) have lost access to public transit relative to choice riders (individuals above poverty who choose to use public transit rather than owning a car). In addition, an analysis of forced-car ownership is conducted to assess whether, over this same period of time, a higher share of "impoverished mobile" individuals have been forced to own a car. The travel behavior (including trip distance and travel time) of both "impoverished mobile" and "choice mobile" groups is compared to assess differences among those two groups. 
Before testing the first hypotheses, an analysis was conducted to see whether and how access to public transit has varied between the two periods studied among all "mobility groups." It was expected that, as neoliberal ideology would predict, access to bus transportation would decrease over that period of time for all mobility groups, due to cuts in funding for bus transit following the logic of monetary efficiency.

As hypothesized, a regression with analysis of interaction between time period and mobility groups (see Tables 10 and 11) showed that all groups lost access to bus transit between 1994 and 2011: they had fewer unique transit lines within 500 meters from home, and these stops were further from home.

Table 10: Number of unique public transit routes within 500 meters from home regressed on years 1994 and 2011

\begin{tabular}{lccc}
\hline & B & S.E. & Significance. \\
\hline (Constant) & 1.580 & 0.066 & 0.000 \\
1994 * Disabled Dependent & 15.225 & 0.8598 & 0.000 \\
1994 * Impoverished Dependent & 15.573 & 0.6502 & 0.000 \\
1994 * Choice Dependent & 12.420 & 0.3976 & 0.000 \\
1994 * Disabled Disadvantaged & 0.397 & 0.8396 & 0.637 \\
1994 * Impoverished Disadvantaged & 7.865 & 1.0584 & 0.000 \\
1994 * Choice Impoverished & 1.449 & 0.4237 & 0.001 \\
1994 * Disabled Mobile & 2.274 & 0.5641 & 0.000 \\
1994 * Impoverished Mobile & 1.584 & 0.2878 & 0.000 \\
1994 * Choice Mobile & 1.180 & 0.0986 & 0.000 \\
2011 * Disabled Dependent & 2.534 & 0.5183 & 0.000 \\
$2011 *$ Impoverished Dependent & 3.223 & 0.4915 & 0.000 \\
2011 * Choice Dependent & 4.480 & 0.453 & 0.000 \\
$2011 *$ Disabled Disadvantaged & 0.163 & 0.4621 & 0.724 \\
$2011 *$ Impoverished Disadvantaged & 0.729 & 0.6689 & 0.276 \\
$2011 *$ Choice Impoverished & 0.156 & 0.4213 & 0.711 \\
$2011 *$ Disabled Mobile & 0.409 & 0.2722 & 0.134
\end{tabular}


$2011 *$ Impoverished Mobile

0.425

0.2306

0.065

$2011 *$ Choice Mobile

Reference

Dependent Variable: number of unique transit service lines

Model: (Intercept), year $2011 *$ Mobility Group

R Square .116. Number of cases: 15,391

Table 11: Distance to nearest public transit station from home regressed on years 1994 and 2011

\begin{tabular}{lcccc}
\hline & B & S.E. & Sig. & Meters \\
\hline (Constant) & 3786.753 & 112.5786 & 0.000 & 1154.2 \\
$1994 *$ Disabled Dependent & -3425.734 & 1467.6343 & 0.020 & 110.0 \\
$1994 *$ Impoverished Dependent & -3438.225 & 1109.9603 & 0.002 & 106.2 \\
$1994 *$ Choice Dependent & -3254.891 & 678.6708 & 0.000 & 162.1 \\
$1994 *$ Disabled Disadvantaged & -2377.245 & 1433.3025 & 0.097 & 429.6 \\
$1994 *$ Impoverished Disadvantaged & -861.848 & 1806.7213 & 0.633 & 891.5 \\
$1994 *$ Choice Impoverished & -1473.153 & 723.2527 & 0.042 & 705.2 \\
$1994 *$ Disabled Mobile & -713.266 & 962.9005 & 0.459 & 936.8 \\
$1994 *$ Impoverished Mobile & -100.987 & 491.2228 & 0.837 & 1123.4 \\
$1994 *$ Choice Mobile & -1065.475 & 168.3115 & 0.000 & 829.4 \\
$2011 *$ Disabled Dependent & -1845.706 & 884.7498 & 0.037 & 591.6 \\
$2011 *$ Impoverished Dependent & -2301.650 & 839.0186 & 0.006 & 452.7 \\
$2011 *$ Choice Dependent & -2808.017 & 773.2762 & 0.000 & 298.3 \\
$2011 *$ Disabled Disadvantaged & -776.064 & 788.8871 & 0.325 & 917.7 \\
$2011 *$ Impoverished Disadvantaged & -1213.089 & 1141.8133 & 0.288 & 784.5 \\
$2011 *$ Choice Impoverished & -1610.542 & 719.1854 & 0.025 & 663.3 \\
$2011 *$ Disabled Mobile & -770.418 & 464.6471 & 0.097 & 919.4 \\
$2011 *$ Impoverished Mobile & -510.702 & 393.6534 & 0.195 & 998.5 \\
$2011 *$ Choice Mobile & Reference &. &. & \\
\hline Dep & & & & 0 \\
\hline
\end{tabular}

Dependent Variable: Nearest distance to transit stop from home in 1994 and 2011

Model: (Intercept), year2011* Mobility Group

R Square 0.006

Changes in the number of bus transit lines, as predicted by the neoliberal effect argument, are partially explained by the consolidation of bus lines - from 118 in 1997 to 79 in 2015 - a 33\% change (Selinger, 2015). In addition, McKenzie (2013) found that levels of transit access declined for neighborhoods of black and Latino concentration in Portland between 2000 and 2009. Perhaps this contributes to explaining why commuting by transit 
in the Portland metro area declined for both Latinos (from 12.4\% to 10.4\%) and Blacks (from $19.4 \%$ to $15.5 \%$ ), between 2000 and 2012 whereas for Whites it remained stable at a $6.8 \%$ rate (see Table 13$)$.

So despite expansions of rail transit service between 1994 and 2011 (MAX light rail added 38 miles, the Westside Express Service rail (WES) added 14.7 miles in 2009, and the streetcar added 8.8 miles (Sellinger, 2015)), the bus system actually diminished its number of bus lines.

In addition, in the early 2000's a frequent service bus network was established, after which TriMet concentrated a larger share of resources on those routes with the best productivity in terms of ridership and efficiency, such as those providing access to hightech firms, located along Portland's rail corridor (Mayer, 2005). And last, in large part caused by the 2007 recession, TriMet had to cut several additional bus routes from 20092012 (Selinger, 2015; McKenzie, 2013). These findings are similar to those of Anbinder (2015) who found that as measured by "annual vehicle revenue miles" in the Portland metro area bus service mileage was reduced between 2006 and 2012 by more than $10 \%$.

\section{Testing Hypothesis 1: "Choice dependent" vs. "Impoverished dependent"}

The first hypothesis related to the question of public transit access posits that access will have improved during the period studied for "choice-dependent" riders (non-poor 
individuals who choose to use transit rather than owning a car) relative to "impoverisheddependent" riders (who cannot afford a car). This hypothesis draws on the city-as-growth machine concept, which would predict that rents would rise in transit-rich central areas the areas that are the focus of so much investment for growth machine actors. This makes housing affordability an issue for low-income residents, leading them to move to outer neighborhoods and suburbs with lower access to transit. Therefore, the analysis below tests whether impoverished-dependent individuals in Portland were worse off over time in terms of access to transit relative to choice-dependent individuals. This means they would have lower frequency of service, fewer transit routes available, and transit stations would be farther from home.

Results of the spatial analysis of access to public transit for the two periods of time are presented in Tables 12-14. An ANOVA analysis shows the number of unique transit lines available and the mean distance from the respondents' households to the nearest public transit station, either MAX light rail or bus in the two studied periods. For 2011, it also shows the average number of unique frequent service lines.

Unsurprisingly, as expected by the workings of the growth machine, access to public transit among the two Dependent groups switched in the two periods of time. In 1994 the Impoverished-Dependent group had better access to public transit than the ChoiceDependent. They had closer access to transit stations (106 m. vs. $162 \mathrm{~m}$.) and access to more unique transit routes (17 routes vs. 14). 
Table 12: Number of transit lines per Mobility Group in years 1994 and 2011

\begin{tabular}{lcc}
\hline \multicolumn{3}{l}{ Number of unique transit service lines } \\
\hline & & 1994 \\
Mobility Groups & $\mathrm{N}$ & Mean \\
Impoverished Dependent & 72 & $17.15^{* * *}$ \\
Choice Dependent & 196 & $14.00^{* * *}$ \\
\% total Sample & 6639 & $3.40^{* * *}$ \\
\hline & $\mathrm{N}$ & 2011 \\
Mobility Groups & Mean \\
Impoverished Dependent & 127 & $4.80^{* * *}$ \\
Choice Dependent & 150 & $6.06^{* * *}$ \\
\% total Sample & 8799 & $1.79^{* * *}$ \\
\hline Sourc: PTAS
\end{tabular}

Source: POTAS 1994 and OTAS 2011.

$* \mathrm{p}<0.05 ; * * \mathrm{p}<0.01 ; * * \mathrm{p}<0.001 ;$

But their relative degree of access to public transit reversed in 2011, so that the Impoverished-Dependent group now had worse access to transit that Choice-Dependent.

Table 13: Number of frequent service lines per Mobility Group in 2011

Number of unique frequent service lines

\begin{tabular}{lcc}
\hline & 2011 & \\
Mobility Groups & $\mathrm{N}$ & Mean \\
Impoverished & 127 & 1.79 \\
$\begin{array}{l}\text { Dependent } \\
\text { Choice Dependent }\end{array}$ & 150 & 1.93 \\
$\%$ total Sample & 8799 & 0.49 \\
\hline Source: POTAS 1994 and OTAS 2011. \\
$* \mathrm{p}<0.05 ; * * \mathrm{p}<0.01 ; * * \mathrm{p}<0.001$.
\end{tabular}

They now had a longer distance from home to transit stops than Choice-Dependent individuals (452 m. vs. 298 m.), and access to fewer unique transit lines within 500 meters from home (4.8 vs. 6.1). 
Table 14: Distance to nearest transit stop from home per Mobility Group in years 1994 and 2011

\begin{tabular}{|c|c|c|}
\hline \multicolumn{3}{|c|}{ Average distance to nearest transit stop from home } \\
\hline & \multicolumn{2}{|r|}{1994} \\
\hline Mobility Groups & $\mathrm{N}$ & Mean (meters) \\
\hline Impoverished & 72 & \\
\hline Dependent & 12 & 100.2 \\
\hline Choice Dependent & 196 & 162.1 \\
\hline$\%$ total Sample & 6639 & 810.5 \\
\hline & \multicolumn{2}{|r|}{2011} \\
\hline Mobility Groups & $\mathrm{N}$ & Mean (meters) \\
\hline Impoverished & 127 & 4527 \\
\hline Dependent & 121 & \\
\hline Choice Dependent & 150 & 298.3 \\
\hline$\%$ total Sample & 8799 & $1,082.9$ \\
\hline
\end{tabular}

Source: POTAS 1994 and OTAS 2011.

$* \mathrm{p}<0.05 ; * *_{\mathrm{p}}<0.01 ; * * * \mathrm{p}<0.001$.

In addition, Tables 13-14 showed that in 2011, choice-dependent riders not only had access to a greater variety of unique transit routes that were closer to home, but they also enjoyed access to more frequent transit lines within $500 \mathrm{~m}$. from home (1.9) than their disabled and poor Dependent counterparts (who had access to 1.8 and 1.4 lines, respectively). Analysis of access to transit frequent service was only conducted for 2011 because frequent service was not provided in 1994.

\section{Testing Hypothesis 2: The case of forced car-ownership}

The second and final hypothesis in this section is related to transit access indirectly. It suggests that 'forced' car ownership will increase for low-income individuals between the two periods studied. Forced car ownership can be seen as a by-product of having poor access to transit. One would thus expect poor individuals, living farther from urban centers in transit-poor neighborhoods, to increasingly become 'forced' car owners. In 
fact, Fred Block's state theory, as discussed in the literature review, would predict such an outcome, since public officials and transportation planners have no incentive to extend bus service to low-income communities in outer neighborhoods. They are more interested in maintaining a healthy business climate. Attempts to extend the state's role by extending bus service would only increase the tax burden on capitalists.

To test this hypothesis, the analysis explores whether the share of "impoverished mobile" individuals (forced car owners) increased over the time period studied relative to other mobility groups.

As predicted by Block's state theory, the impoverished-mobile group experienced a 37\% decrease in access to unique transit routes between 1994 and 2011 (see Table 12), perhaps due to a higher share of them living in the periphery. This finding supports Currie's research (2009) related to the fact that forced car ownership is mainly a phenomenon of the urban periphery, due to its core elements: low-income, a need for travel and lack of transportation alternatives. The Impoverished-Mobile traveled half the distance of the Choice-Mobile (16.5 miles in 2011), reflecting a closer range of destinations, and thus higher levels of social exclusion. This huge difference in traveled distance may also suggest the high cost of driving for Impoverished Mobile individuals, who might as a result be limiting their travel.

As might be expected, all of the Mobile groups (those who drive) had the fewest number of transit lines available from home and the longest distance to transit stations. One important difference between Mobile groups is that while Mobile-Choice individuals may 
choose to live in areas with poor access to transit, Impoverished Mobile individuals are not there by choice. They cannot afford to live in transit rich neighborhoods, leaving them with no choice but to live in transit-poor neighborhoods and be forced to drive.

Table 15 compares travel mode to work by race in the Portland metro area between 2000 and 2013. If minorities are living in the suburbs, one would expect them to be driving more than before and taking transit less. Single occupancy commuting slightly decreased for Whites, but indeed increased for Blacks and Latinos: Between 2000 and 2013 the percentage of people who drove alone to work increased from $57 \%$ to $66 \%$ for Blacks, and the proportion living outside of the City of Portland increased from about 37 percent in 2000 to about 43 percent in 2010 (U.S. Census Bureau 2011)- and from 53\% to 61\% for Latinos. During the same period poverty levels increased from $24 \%$ to $34 \%$ for Blacks and from 23\% to 28\% for Latinos (Census, 1990 and 200; ACS 2013) (see Appendix, Table 3).

Table 15: Means of transport to work by race/ethnicity, Portland 2000 and 2013

\begin{tabular}{|c|c|c|c|c|c|c|}
\hline \multicolumn{7}{|c|}{ Census 2000} \\
\hline & White & & Black & & Latino & \\
\hline & $\mathrm{N}$ & $\%$ & $\mathrm{~N}$ & $\%$ & $\mathrm{~N}$ & $\%$ \\
\hline Drive & 457011 & 73.3 & 9,688 & 57.4 & 26,728 & 53.4 \\
\hline Carpool & 63,420 & 10.2 & 2,530 & 15.0 & 12,491 & 25.0 \\
\hline Public transit & 42,493 & 6.8 & 3,280 & 19.4 & 6,184 & 12.4 \\
\hline Bicycle & 5,650 & 0.9 & 143 & 0.9 & 397 & 0.8 \\
\hline Walk & 19,360 & 3.1 & 597 & 3.5 & 2,346 & 4.7 \\
\hline \multicolumn{7}{|c|}{ ACS 2013} \\
\hline & White & & Black & & Latino & \\
\hline & $\mathrm{N}$ & $\%$ & $\mathrm{~N}$ & $\%$ & $\mathrm{~N}$ & $\%$ \\
\hline Drive & 511,851 & 69.9 & 15,521 & 66.1 & 55,420 & 61.3 \\
\hline Carpool & 63,738 & 8.6 & 2,235 & 9.4 & 16,180 & 17.5 \\
\hline Public transit & 47,140 & 6.8 & 3,505 & 15.5 & 8,558 & 10.4 \\
\hline Bicycle & 26,000 & $4.0 *$ & 540 & $2.5^{*}$ & 2,244 & $2.7^{*}$ \\
\hline Walk & 24,060 & 3.7 & 441 & 2.3 & 4,111 & 5.0 \\
\hline
\end{tabular}


Census 2000, ACS 2009-2013. *This figure includes, taxi, motorcycle, bicycle, and other.

Table 16 shows the results of a regression to explore whether changes in the amount of driving (alone) occurred for the impoverished-mobile between 1994 and 2011. Results indicated that indeed driving increased among the impoverished-mobile group $(B=.161$, $\mathrm{SE}=.031, \mathrm{p}<.000)$.

The reason for this increase in driving (alone) might be a response to: 1) an increase in distance to work, 2) an increase in the share of individuals living in the suburban counties in 2011, and 3) an increase in poverty levels in 2011, compared to 1994 among impoverished-mobile individuals. These figures suggest that there is an increase in 'forced' car-ownership among socially disadvantaged individuals who increasingly rely on cars to achieve their mobility levels, with the economic burdens that this represents.

Table 16: Driving alone regressed on period of time

\begin{tabular}{lccc}
\hline & B & S.E. & Significance \\
\hline (Constant) & .596 & .005 & 0.000 \\
$2011 *$ Impoverished Mobile & .161 & .031 & 0.000 \\
\hline
\end{tabular}

Source: POTAS 1994 and OTAS 2011.

a.Dependent Variable: Drive alone. R Square .085

\subsection{Analyzing the journey-to-work}

Inequality in the journey-to-work is the second major area of research in this study. The hypotheses based on the research question here draw on a body of theories around "social relations in the household," "inequalities in the job market," and "residential location."

Research Question: How do gender, race/ethnicity, and income inequality affect the journey-to-work? 
Three hypotheses were tested in answering this question:

- Hypothesis 3 (Gender): The journey-to-work will be shorter for women than for men.

As the literature review showed, studies on "social relations in the household" explain in detail how women must balance dual roles as housewives and wage earners, and how shorter work trips enable them to coordinate their many activities (MacDonald, 1999). In addition, research on "inequalities in the job market" shows that women, who tend to hold low-paid, part-time jobs in the service sectors, are more likely to find employment closer to home.

- Hypothesis 4 (race/ethnicity): The journey-to-work will be longer for minorities than for everyone else.

This is the expected outcome of the work on "residential location," which posits that minorities in lower- cost neighborhoods with few local employment opportunities seek and take jobs farther away.

- Hypothesis 5 (Class): The journey-to-work distance will be shorter for lowincome individuals than for everyone else.

This would be consistent with research looking at the relationship between journey-towork and class, which has found that low-income individuals in general travel shorter distances to work due to lower levels of mobility than those with higher incomes. Lucas (2012) shows how lack of mobility is associated with social exclusion, since the poor cannot reach opportunities due to lack of a car or sometimes even the means to afford transit. Income not only affects a person's ability to own a car, but also, as Doyle et al. 
(2000) show, their choice of residential location. Low-income individuals tend to live in low-income neighborhoods with low-paying jobs.

\section{Testing Hypothesis 3: The role of "social relations in the household" and "inequalities in the job market" in explaining the journey to work}

It was hypothesized that the journey to work will be shorter for women than men. Reasons for this draw on two bodies of research around: "social relations in the household" and "inequalities in the job market." Research on "social relations in the household" explains in detail how women must coordinate dual roles as housewives and wage earners, and how shorter work trips enable them to coordinate their many activities (MacDonald, 1999). Similarly, research on "inequalities in the job market" explains why women, who tend to hold low-paid, part-time jobs in the service sectors, are more likely to find employment closer to home, and thus have shorter commutes.

Results of a regression analysis of journey-to-work distance regressed on gender, income and race (see Tables 17 and 18) showed a negative relationship between gender and journey-to-work distance and commuting time, meaning that women made shorter trips to work than men, because on average they lived significantly closer to their workplaces than men, with the exception of Black women in 2011. These results support MacDonald's research (1999), which posits that shorter work-trips enable women to coordinate their many activities as mothers and workers. 
Table 17: Journey-to-work distance regressed on gender, race, income and year

\begin{tabular}{lccc}
\hline & $\mathrm{B}$ & Std. Error & Significance. \\
\cline { 2 - 3 } & Distance in miles & & \\
\hline (Constant) & 7.270 & .141 & .000 \\
Female & -1.492 & .281 & .000 \\
2011 Black Female & 1.750 & 1.733 & .313 \\
Low-income*2011 & -1.678 & .468 & .000 \\
\hline
\end{tabular}

a. Dependent Variable: straight-line distance home to fixed workplace location

R Square .004.

Table 18: Journey-to-work time regressed on gender, race and income

\begin{tabular}{lccc}
\hline & \multicolumn{1}{c}{$\mathrm{B}$} & Std. Error & Significance. \\
\cline { 1 - 2 } & Distance in minutes & & \\
\cline { 2 - 2 } (Constant) & 44.176 & 1.062 & .000 \\
Female & -8.642 & 1.484 & .000 \\
2011 Black Female & 26.472 & 10.489 & .012 \\
Low-income & -3.380 & 2.123 & .111 \\
\hline
\end{tabular}

a. Dependent Variable: Work travel time

R Square .009.

Testing Hypothesis 4: The role of "residential location" in explaining the journey to

work

Hypothesis 4, which predicts that the journey-to-work will be longer for minorities than for everyone else is tested using the research on "residential location," which has found that minorities in lower- cost neighborhoods have few local employment opportunities and therefore need to seek (and take) jobs farther away. Thus, this study hypothesized that the journey-to-work would be longer for minorities than for everyone else. There were not enough cases in the surveys to meaningfully analyze groups at the intersection of race, gender and class.

\section{Blacks}


Tables 19 and 20 showed that Blacks in metropolitan Portland, as hypothesized, had the longest average work commutes of any racial group in 2011. Interestingly, Blacks experienced the largest increase in distance to work and in travel time between 1994 and 2011. This is consistent with the data on residential location of Blacks in metropolitan Portland, which shows an increasing share living in the outer neighborhoods and suburbs since 1994, perhaps in large part due to displacement from a gentrifying core and housing discrimination.

Table 19: Journey-to-work time regressed on gender, race and income

\begin{tabular}{lccc}
\hline & B & Std. Error & Significance. \\
\hline (Constant) & Distance in miles & & \\
Female & 44.176 & 1.062 & .000 \\
2011 Black Female & -8.642 & 1.484 & .000 \\
Low-income & 26.472 & 10.489 & .012 \\
\hline
\end{tabular}

a. Dependent Variable: Work travel time

b. R Square .009.

Table 20: Journey-to-work distance regressed on gender, race and income

\begin{tabular}{lccc}
\multicolumn{1}{c}{ B } & Std. Error & Significance. \\
\cline { 1 - 1 } (Constant) & Distance in miles & & \\
Black & 6.930 & .116 & .000 \\
Latino & 1.670 & 1.897 & .379 \\
Black women & -.061 & .665 & .927 \\
\cline { 1 - 2 } & -.409 & 2.401 & 865 \\
\hline
\end{tabular}

c. Dependent Variable: Distance to work

d. R Square .007. 
It is likely that growing poverty among Blacks in Portland ${ }^{4}$ has contributed to their shift to lower-cost neighborhoods in the suburbs. Thus, a longer distance to work from home might be a response to a higher share of Blacks in 2011 living both below poverty and in suburban counties than in 1994.

When living in the core, work commutes were shorter for Blacks since many available jobs were nearby; but when living in outer neighborhoods and suburbs, work commutes are farther due to fewer job options nearby and ongoing discrimination in the job market (Massey and Denton 1993; Hogan and Berry 2011). This forces Black residents to seek and take jobs farther away.

The findings in Portland are consistent with the research on residential location of minorities, such as Giuliano's work (2000), which shows that inequalities in both the housing and job markets translate into the need for Blacks to travel longer distances to reach their jobs and take a longer time. The longer travel times in part reflect greater reliance on public transit. This is true in fact in Portland, for both the general population (See Table 13) and the study sample population (see Appendix, Table 4), where Blacks have the highest share of any racial group using public transit for the journey-to-work. Giuliano (2000) maintains that riding transit, which generally takes much longer than driving, is a result of lower incomes.

\footnotetext{
${ }^{4}$ The percentage of Blacks below poverty in metropolitan Portland increased from $23.6 \%$ in 2000 to $34.1 \%$ in 2013. This was the largest increase among any racial group. See Appendix, Table 3).
} 
The huge increase in both distance to work for Blacks between 1994 and 2011 seems to support Kain's spatial mismatch theory (1968), but with a twist. Kain argued that Black low-income workers in the core were mismatched to their suburban jobs, in part due to their residential segregation in lower-cost neighborhoods in the central city that offered few local employment opportunities. While the Portland analysis confirms a spatial mismatch between Blacks and their jobs, the twist is that by 2011 more Blacks were living in Portland suburbs (see Appendix, Table, 2) and were mismatched to jobs in the core or in other suburbs. In fact, Blacks in Portland had the highest share of "mismatched" workers: $42 \%$ of Blacks worked in a different county than where they lived, compared to only $33 \%$ of Whites and $34 \%$ of Latinos (Appendix, Table 5).

$\underline{\text { Latinos }}$

In contrast to Blacks, Latinos in Portland have followed a different population growth pattern, which affects their journey-to-work differently. The Latino share of the metropolitan population increased from 3.4\% in 1990 to 11.7\% in 2010 (See Appendix, Table 1). Contrary to what "residential location" research would predict (that minority groups tend to be moving to lower-cost suburbs), Latino populations have increased fairly equally in all three counties of Portland's metropolitan area (See Appendix, Table 2). As a result, their journey-to-work travel time and distance looks very similar to those of Whites. 
The results of the journey-to-work analysis by race have shown that in Portland, “minorities" cannot be considered a monolithic group. Massey $(1993,1996)$ and other researchers tended to focus on Blacks as the "minority" group, without looking at behaviors of other minorities such as Latinos. While the journey-to-work characteristics of Blacks in Portland are consistent with the literature on race and journey-to-work, Latinos in Portland follow a different pattern. Their journey-to-work characteristics more closely resemble Whites.

Growing poverty rates and an increasing population of Blacks in the suburbs is not in itself evidence of gentrification or involuntary displacement. Yet, this is a plausible hypothesis supported by research in Portland (McKenzie, 2013; Gibson, 2004, 2007, 2013). It's reasonable to assume that under the circumstances described above, it has become more difficult for Blacks to afford living in central city neighborhoods in Portland.

\section{Testing Hypothesis 5: The role of income level in explaining the journey to work}

Since income level is a mechanism that identifies the economic attributes that shape people's opportunities, such as job type, choices and material conditions, it may also explain differences in the journey-to-work (Wright, 1996, 1997, 2005). It was hypothesized that the journey to work will be shorter for low-income individuals than for higher-income groups. Research on the relationship between class (or income level) and the journey-to-work has found that low-income individuals - who tend to be less educated 
and hold lower-paid jobs than middle- and high-income individuals - are more likely to seek and take employment closer to home, a key reason for their shorter commutes. Massey's $(1993,1996)$ research supports this argument. He shows that income inequality and class segregation overwhelmingly affect individuals' travel behavior, due to the types of work they are able to obtain.

In addition, the poor have lower rates of car ownership than higher-income individuals, so they must rely more often on transit or car-pooling, which are slower modes of transportation and might limit how far away an individual is willing to work. Lucas (2012) shows how lack of mobility is associated with social disadvantage and exclusion, since the poor cannot reach opportunities due to lack of a car or sometimes even the means to afford transit.

A regression of travel time and journey-to-work distance on individuals at different income levels (controlling for other variables) showed that lower-income individuals in the metropolitan Portland area traveled shorter distances to work than wealthier commuters in both 1994 and 2011 (see Table 21). The average journey-to-work distance for the low-income group over the entire period studied was 5.6 miles, compared to the middle- and higher-income groups at 7.2 miles each. These results match the research showing that lower income individuals have shorter journeys to work (Giuliano, 2000, 2005; Krovi et al, 2000; Crane, 2007). 
Table 21: Journey-to-work distance regressed on income, period of time and race

\begin{tabular}{lccc}
\hline & B & Std. Error & Significance. \\
\cline { 2 - 3 } & Distance in miles & & \\
\hline (Constant) & 7.364 & .771 & .000 \\
Low-income & -1.662 & .491 & .001 \\
Middle-income & .115 & .266 & .666 \\
Black & .222 & 1.217 & 855 \\
\hline
\end{tabular}

e. Dependent Variable: Distance to work

f. R Square .005.

Another interesting finding worth mentioning is that although low-income individuals in Portland traveled the shortest distances of any income group, their commuting times were significantly higher than for higher income groups in 2011- likely due to higher levels of use of public transportation.

Table 22: Journey-to-work time regressed on income, period of time and race

\begin{tabular}{lccc}
\hline & B & Std. Error & Significance. \\
\hline (Constant) & 38.370 & 1.231 & .000 \\
Low-income & 2.160 & 2.875 & .085 \\
Black & 9.141 & 8.059 & .257 \\
\hline
\end{tabular}

g. Dependent Variable: Distance to work

h. R Square .001.

\subsection{Analyzing "Household-serving" trips}

In this section, differences in household-serving trips by gender among different family types are analyzed. One research question is asked and one hypothesis is tested drawing on a body of theories around "gender socialization":

Research Question: Do household-serving trips vary by gender in Portland?

- Hypothesis 6: Women will make more household-serving trips than men. 
The reason for more household-serving trips by women, according to the set of theories around "gender socialization," is that a strong division of roles - with women assigned to "women's work" and men to "men's work" - means that women in general make more child-serving and grocery shopping trips (i.e., doing “women's work”) than men.

\section{Testing the "gender socialization" hypothesis}

To answer the research question and test the hypothesis that women will make more house-serving trips than men, the study looked at four family types: 1) individuals living alone ("one-person households"), 2) couples with no children, 3) couples with children, and 4) single parents.

An statistical descriptive analysis was conducted on the data (number, time, and distance of household-serving trips among the four family types). The results (see Appendix, Table 7) showed that in terms of household-serving trips women in general made more trips -with the exception of women living alone and single mothers- and had longer and lengthier trips than men, confirming the hypothesis. Among women in all family types, those with children traveled longer distances than childless women, and those living alone traveled the shortest distances.

These results are consistent with the related finding that women in Portland still do the majority of household and childcare chores. As expected, the lowest gender gap in both household maintenance and work related activities was among childless households (see 
Appendix, Table 6). As Taylor et al. (2015) and Rosenbloom (2006) found, the disproportionate parenting and household responsibilities of women lead to more household-serving trips.

Overall, in keeping with the "gender socialization" hypothesis, women's share of household maintenance activities as a share of all activities was higher than men's share in every family category. Although, the sharpest differences were among women with children, particularly within couples with children. Interestingly, the share of household activities among men from the family categories.

In addition, a set of regressions were conducted to test the "gender socialization" hypothesis, with the number of household-serving trips, trip time, and travel distance regressed on the four family types (see Tables 23-25). Results from this model showed that:

First, in terms of number of household-serving trips (See Table 24), women living alone and single mothers made fewer household-serving trips than similar men. Perhaps fewer trips are a factor of the longer travel times that single mothers spent travelling due their huge reliance on public transit as opposed to single father who had high access to vehicles. This may also reflect the fact that single mothers are time poor due to the need to conduct their activities alone. In contrast, women from the household categories: "couples with 
children" and "couples with no children" made more household-serving trips than similar men, suggesting that the additional work related to childbearing rests mostly on women.

Second, women in the four family categories spent longer time making householdserving trips, though only those made for women with children were significant (See table 23).

Third, women from "households with children" and "one-person households" traveled longer distances (See Table 25) than men in household-serving trips (though results were not significant).

Table 23: Number of household-serving trips regressed on household type by gender

\begin{tabular}{lccc}
\hline \multicolumn{1}{c}{ B } & & Std. Error & Significance \\
\hline (constant) & 3.838 & 0.142 & .000 \\
One person household women & 0.131 & 0.207 & 0.527 \\
Couples no children women & -0.125 & 0.155 & 0.419 \\
Couples with children women & 0.111 & 0.111 & 0.319 \\
Single parent women & -0.050 & 0.256 & 0.846 \\
One person household men & 0.497 & 0.304 & 0.102 \\
Couples no children men & -0.158 & 0.153 & 0.302 \\
Couples with children men & -0.236 & 0.107 & 0.028 \\
Reference single parent men & & & \\
\hline
\end{tabular}

R Square .023

$\mathrm{N}(1994$ and 2011 sample= 13,073).

Table 24. Household-serving trip time regressed on household type by gender

\begin{tabular}{lccc}
\hline \multicolumn{1}{c}{ B } & & Std. Error & Significance \\
\hline (constant) & 16.348 & 0.569 & 0.000 \\
One person household women & 0.774 & 0.649 & 0.233 \\
Couples no children women & 0.608 & 0.544 & 0.264 \\
Couples with children women & 7.382 & 0.564 & 0.000 \\
Single parent women & 8.498 & 1.52 & 0.000 \\
One person household men & -0.672 & 0.811 & 0.408 \\
Couples no children men & -0.323 & 0.546 & 0.554 \\
Couples with children men & 1.692 & 0.567 & 0.003 \\
Reference single parent men & & & \\
\hline
\end{tabular}

R Square .018 
N (1994 and 2011 sample= 13,073).

Table 25: Household-serving trip distance regressed on household type by gender

\begin{tabular}{lccc}
\multicolumn{1}{c}{ B } & Std. Error & Significance \\
\hline (constant) & 2.558 & 1.518 & 0.092 \\
One person household women & 0.252 & 1.732 & 0.884 \\
Couples no children women & 0.604 & 1.452 & 0.677 \\
Couples with children women & 1.952 & 1.506 & 0.195 \\
Single parent women & 1.353 & 1.056 & 0.739 \\
One person household men & 0.044 & 1.165 & 0.984 \\
Couples no children men & 3.912 & 1.456 & 0.007 \\
Couples with children men & 1.095 & 1.513 & 0.469 \\
Reference single parent men & & & \\
R Square .001 & & \\
N (1994 and 2011 sample= 13,073). & &
\end{tabular}

Results showed that among "couples with children" women made more trips and travelled farther and significantly longer than their male counterparts. Among women, women with children made more household-serving trips and travelled farther and longer than childless women.

The results therefore seem to confirm that having children increases the number of household-serving trips for women. This is consistent with the literature that shows that women with children have more complex daily activity patterns, associated with family duties and child responsibilities, than men with children, and women and men without children.

As Taylor et al. (2015) show, the role and influence of gender ideology is remarkably strong in explaining why women make more child-serving and grocery shopping trips. The results in this section further confirm gender socialization theories around the unequal division of housework that reflect gender ideologies. Women end up with a 
disproportionate share of household-related errands such as taking children to school and appointments, and grocery shopping.

In this chapter, six hypotheses were tested through statistical analyses, comparisons of data over time, and interpretation of secondary sources. The hypotheses drew on a body of relevant theories centered on the three key questions of this dissertation. All of the findings supported the hypotheses in general, although there were minor variations at the intersections of race, gender and class. However, the available data in many cases was insufficient to endow many variations with significance - there was simply not enough data collected from minority populations (this issue is discussed in detail in the research design chapter). The final chapter of this dissertation reviews and discusses in further detail the key findings from this research, and ends with some conclusions and recommendations. 


\section{Chapter 5. Findings and Discussion}

This study has seven main findings, grouped here by the relevant transportation inequality metric to which they apply.

\subsection{Access to transit findings}

One key question of this dissertation is the effect of neoliberalism on access to public transit in Portland. Since neoliberal ideology seeks to reduce the social welfare state, it was expected that the bus system would suffer from cutting costs, which was actually the case. An analysis of the data showed that access to bus transit decreased for all groups between 1994 and 2011 in the Portland metro area, particularly among socially disadvantaged groups.

The neoliberal effect shifted the bus system from its earlier purpose of providing a public service for those who have no other option toward an economic purpose focused on relieving traffic congestion, and on efficient routes that pay for themselves in places where ridership is high. Portland transit systems also witnessed a turn toward rail investment rather than bus, illustrating how meeting human needs in the neoliberal era becomes subordinate to the imperatives of capital accumulation.

Second, as predicted by Hypothesis 1, drawing on the growth machine thesis of urban political economy, impoverished-dependent riders (those too poor to own a car, who thus rely on transit) became more "transportation-disadvantaged" in metropolitan Portland between 1994 and 2011 than choice-dependent riders (who depend on transit by choice). Impoverished-dependent riders had fewer transit routes available and lower frequency of 
service, and were required to make longer journeys on foot to get to bus stops or light rail stations. In contrast, the choice-dependent group in Portland has the greatest access to transit in terms of distance to stops, frequency of service, and diversity of route options. One reason seems to be that choice-dependent individuals can afford to live in transit-rich neighborhoods, where it is easier to choose not to own a car but to rely on transit instead. This is consistent with the concept of an "urban growth machine," which states that in the competition to grow the city, elites focus on improving the core where returns and profits are high and they can benefit from the resulting rise in rents. However, these rising rents cause low-income individuals to seek housing elsewhere, which is most often in a transitpoor, outer neighborhood or suburb, as was found to be the case in metropolitan Portland.

The third finding from this research is that, as predicted by Hypothesis 2 and supported by Block's theory of the capitalist state, the share of impoverished-mobile individuals (low-income individuals who own cars) in metropolitan Portland grew significantly during the time period studied. Most likely, many of those individuals are "forced car owners." A plausible explanation for this growth of "forced car ownership" is that a higher share of low-income individuals live in the suburbs, with lower access to public transit. This finding is consistent with Fred Block's theory of the capitalist state, which posits that in order to maintain a healthy business climate, government bureaucrats (including transportation planners), agency heads, and other "state managers" are reluctant to extend the state's role because it would increase the tax burden on businesses. Thus transportation officials would be reluctant to expand bus service within low-income 
communities on the periphery of the city, as this would increase the state's role as well as the tax burden on businesses, creating a less friendly business climate. Since a growing share of low-income individuals in Portland are now living in these transit-poor neighborhoods on the outskirts of the city, more low-income individuals are forced to purchase a car in order to get around.

\subsection{Journey-to-work findings}

A fourth and important finding is that overall, women in Portland live a mile closer to work than men (6.3 mi vs. $7.3 \mathrm{mi})$ and have shorter round-trip journeys to work than men (46 min vs $50 \mathrm{~min})$. They are also more likely to ride transit to work than men (14\% vs $11 \%)$, and they drive to work less frequently than men (73\% vs $74 \%)$. That said, women are not a monolithic group; there are important differences in commuting behavior among them when race and ethnicity are taken into account. For example, White women show lower use of public transit and have a shorter travel time, although overall they travel similar distances as women of color. In addition, the lowest gender gap in travel mode is among Whites: there are not relevant gender differences in driving and transit use among them. All of these findings support Hypothesis 3, which postulated that due to unequal social relations in the household and inequalities in the job market, the journey-to-work was shorter for women than for men.

Research on "social relations in the household" support this hypothesis, explaining in detail how women must coordinate dual roles as housewives and wage earners, and how shorter work trips enable them to coordinate their many activities (MacDonald, 1999). Other research supporting Hypothesis 3 focuses on inequalities in the job market and 
finds that women, who tend to hold low-paid, part-time jobs in the service sectors, earn less, and work shorter hours, are more likely to seek employment closer to home to reduce time spent travelling (MacDonald, 1999; Madden, 1981).

A fifth finding from the research is that, as Hypothesis 4 proposed, the journey-to-work was longer for minorities, particularly Black, than anyone else. One reason is that minorities tend to live in lower-cost, isolated neighborhoods with few local employment opportunities. This hypothesis draws on "residential location" theory, which has found that Blacks - who tend to live in lower-cost isolated neighborhoods with few local employment opportunities nearby - must seek and take jobs farther from their homes than whites, in part due to scarcity of employment opportunities near where they live but also due to racial discrimination.

In the Portland metro area, Black individuals have the lengthiest distance to work and the longest travel time of all groups. Among just women, Black women on average traveled further to work; had the longest average commute time and the highest use of public transit than White and Latino women.

Residential location theory, as described above, seems to make sense for Blacks in Portland, since between 1994 and 2011 the share of Blacks living in Multnomah County decreased as many Blacks were displaced to less-expensive and more isolated suburban communities (the proportion of Blacks living outside of the City of Portland increased from about 37 percent in 2000 to about 43 percent in 2010 (U.S. Census Bureau 2011)). 
The huge increase in both distance to work and commute time for Blacks between 1994 and 2011 seems to support Kain's spatial mismatch theory (1968), but with a twist: Kain argued that Black low-income workers in the core were mismatched with available jobs in the suburbs due to their residential segregation in lower-cost neighborhoods in the central city that offered few local employment opportunities. While the Portland analysis confirms a spatial mismatch between Blacks and their jobs, the twist is that by 2011 more Blacks were living in Portland suburbs (see Appendix, Table 2) and were mismatched to available jobs in the core (and in other suburbs) -the reverse geography of Kain's spatial mismatch theory. In fact, Blacks in Portland had the highest share of "mismatched" workers: $42 \%$ of Blacks worked in a different county than where they lived, compared to only $33 \%$ of Whites and $34 \%$ of Latinos (Appendix, Table 5).

Sixth, as hypothesis 5 predicted, the journey-to-work distance was shorter for lowincome individuals than for everyone else, since they tend to seek and obtain low-paying jobs close to home (typically a low-income neighborhood). This hypothesis draws on research on the relationship between journey-to-work and class, which has found that low-income individuals in general travel shorter distances to work due to lower levels of mobility than those with higher incomes. Such lack of mobility has social implications since it is associated with social exclusion, because the poor cannot reach opportunities due to lack of a car or sometimes even the means to afford transit.

This trend reflects a "mode gap" among lower-income individuals, who use public transit, a slower mode, more often than the non-poor. In contrast, longer distances and 
shorter travel times of wealthy individuals might reflect not only their ability to choose the most convenient transportation mode and residential location, but it also reflects a wider set of jobs, services and recreational activities available for them. These results support Mauch and Taylor's (1997) findings regarding income being important in understanding the shorter commutes of poor individuals, because lower income groups share common economic and social characteristics, residential location, and occupation. These results have inequality implications because the lower distances traveled impact the quality of jobs and service range these socially disadvantaged individuals have access to.

\subsection{Household serving trips findings}

Seventh, results supported hypothesis 6 , that posits that women in general made more household-serving trips than men, draws on the "gender socialization" theory which states that gender roles are the primary determinants of the division of work. Women are assigned to "women's work" and men to "men's work." The consequence of such a strong division of roles is that women in general make more child-serving and grocery shopping trips (i.e., "women's work") -with the exception of women living alone and single mothers- than men. Thus: being female increases the number, duration and distance of household-serving trips, in particular for women with children. In contrast, men made more trips, traveled further and longer than women, regarding both discretionary and work-related trips. These results have important transportation and 
gender equity implications, since the division of house-work seems to be a factor of gender roles: women are more likely to be assigned to "women's work", such as chauffeuring the children and doing the grocery shopping, reflecting beliefs about the appropriate roles and behaviors of men and women. Results also showed that women with children have more complex daily activity patterns associated with a disproportionate share of family duties and child responsibilities, than men and childless women. 


\section{Chapter 6. Conclusions and Recommendations}

The idea for this dissertation began with a simple question: how is metropolitan

Portland, so often held up as a model of sustainable transportation and land use planning, addressing questions of equity in transportation outcomes? And is a move to greater equity even possible in an era infused by neoliberal ideology? Three inter-related research questions were explored:

1. What has been the effect of neoliberalism on access to public transit in metropolitan Portland?

2. How do gender, race/ethnicity, and income inequality affect the journey-to-work?

3. How does gender inequality affect household-serving trips in Portland?

The scope of this dissertation was admittedly very broad, but looking at all three of these transportation aspects and their unequal outcomes was also useful in showing how pervasive the effects of neoliberal ideology can be. The fact that unequal outcomes were found in areas of transportation as different as access to public transit, the journey-towork, and household-serving trips - and that these outcomes disproportionately affected women, the poor, and racial minorities - tells us much about Portland's priorities in transportation and land use planning in a neoliberal era.

While it was not possible to conduct as deep an analysis on each question as might have been the case had the focus been on only one question, the results were sufficient to make some preliminary conclusions and recommendations, and map out a path for future research. 
After testing the set of six hypotheses and examining the findings (Chapters 4 and 5), a key conclusion to be drawn is that efforts to implement smart growth and sustainable transportation policies in Portland have been (however unwittingly) favoring those with privilege (e.g., Whites, males, and higher income individuals) over the least advantaged social groups.

The study found that those who ride transit by choice are being favored over those who depend on transit; those who can afford to live in the gentrifying core of Portland have more transit opportunities than those who can only afford to live in the transit-poor periphery; White workers are benefitting more than Black workers in Portland (as shown by journey-to-work comparisons); and men in general are still better off than women in terms of household-serving trips (despite evidence that the gender gap is closing in terms of jobs and pay). Although the situation has been improving over time, it is clear that, in terms of key mobility metrics, gaps between Blacks and Whites, men and women, rich and poor still persist, and in some cases are widening.

Examining the effect of the intersections of income level, race and gender on transportation outcomes reveals even further disadvantages. Multiple factors of disadvantage, such as being female, Black and poor, when taken together, increase the magnitude of the negative effects. Unfortunately, a deeper analysis of such "complex inequality" was not possible with the available data sets, given the low number of minority responses. 
A hallmark of neoliberal ideology is its emphasis on efficiency over equity. This emphasis may prove to be misplaced, however, when one looks at the bigger picture. As future research may show, providing public transportation as a service to the poor might actually contribute to growing the market economy by fueling the social mobility of lowincome groups, allowing them greater access to services, jobs, and opportunities. They become more competitive in the marketplace as inequalities in access to transit are reduced.

A key recommendation from this research, therefore, is for transportation planners to refocus their efforts on providing public transportation as a service for disadvantaged groups, and not as a tool to decrease traffic congestion in the name of efficiency or as a way to shift people from driving to transit in the name of sustainability. This is especially important in a context of growing income inequality.

Another recommendation is to find ways of strengthening the regulatory capabilities of the state. Allowing "the market" to write the rules by which public transportation or housing is provided will make things worse, widening the gaps among the haves and have-nots and eroding any social cohesion.

A political economic framework was employed to study transportation outcomes in Portland - an approach not often found in the literature. The application of theories critical of neoliberal ideology, such as Block's theory of the capitalist state and Molotch's 
"growth machine" theory to the area of transportation research offers a modest contribution to filling the gaps in the literature in this type of research. The study showed the downside of Portland's sustainable city image, including the negative effects of gentrification on low-income residents and their ability to meet their travel needs.

Block's theory of the capitalist state and Molotch's growth machine theory were useful in explaining the unequal outcomes found through the data analysis. However, neither theory examines differences at the level of gender or race. As Melissa Gilbert (1999) have suggested these theories would benefit from incorporating such social dimensions to increase their robustness as explanatory theories and offer a more nuanced critique of neoliberalism. For example, it is clear that neoliberal policies have affected differences in the journey to work (by race, income level, and gender), but for the purposes of this study it was necessary to employ other theories besides growth machine and state theory to explain outcomes along these dimensions. These other theories focused on residential location, social exclusion, and gender relations in the household and job market.

As mentioned above, critiques of neoliberalism and the capitalist state are rarely applied to the field of transportation research. That said, a political economic framework was useful in identifying findings with potentially great social relevance. For instance, finding lower levels of access to public transit among socially disadvantaged individuals has implications for worsening social exclusion under neoliberalism. Low access to transit restricts access to jobs, services, and leisure activities and increases levels of forced car- 
ownership, all of which have negative effects on society. Forced car owners are more likely to restrict their travel to save money on fuel and maintenance, exacerbating social exclusion. State theory and growth machine explain how such winners and losers are produced by the workings of a capitalist state with weak government regulation.

It is important, therefore, that urban policy-makers and planning staff consider the negative consequences of their focus on enhancing the core; otherwise new transportation investments aiming to improve mobility and accessibility will continue to benefit 'choice' riders over those who depend on transit. Although housing affordability and residential location were not the main focus of this research, results suggested that involuntary displacement of disadvantaged groups due to rising housing prices was an unintended consequence of Portland's attempts to enhance the core and increase the mode share of transit, walking, and bicycling.

Those who need transit the most, paradoxically, have been losing access to it in Portland. Providing socially disadvantaged households with improved access to affordable housing in transit-rich neighborhoods would be an important strategy for decreasing social exclusion. It would require better coordination between housing, land-use, and transportation policies.

If a more inclusive future for Portland is desired, the market cannot continue defining housing policy and transit planning. It seems that urban renewal, redevelopment, and 
densification policies in Portland have at the very least accelerated the displacement of low income and minority populations - particularly African Americans - to the periphery. Clearly, strong demand-side pressures may make matters worse, but it's the responsibility of policy makers to find a balance that takes social equity into account. The breadth of this study has not only helped identify a range of inter-related findings and enabled a broad set of conclusions and recommendations, it has also provided a rich agenda for further research. This includes examining such topics as:

- The effects of the intersections of race, class, and gender in unequal transportation outcomes (i.e., complex inequality).

- The trend toward convergence of commute times for women and men (as women gain ground in the job market), while at the same time differences remain in household-serving trips, with women continuing to do the majority of household work and childcare. Women's extra burdens appear to be long-standing; perhaps things haven't changed much since Madden's (1981) seminal paper on the topic.

- An update to spatial mismatch theory. Instead of Blacks in the core mismatched with available jobs in the suburbs, Portland now shows the opposite after over two decades of displacement: Blacks are now in the suburbs, yet the majority of jobs available to them are in the core. Perhaps it doesn't matter where Blacks live; discrimination will lead to a spatial mismatch between whatever neighborhoods they inhabit and the location of jobs most available to them. It would be interesting to explore whether this holds true in other cities that have experienced high levels of gentrification, and what it implies for spatial mismatch theory.

This study also uncovered a problem with the two transportation surveys used for the analysis: minorities were underrepresented in both surveys, and this paucity of data prevented the discovery of statistically significant findings. This opens an agenda for transportation planners in Portland to collect data in a way that accurately represents the heterogeneity of a complex society. It is clear that the under-representation of racial 
minorities and the poor represents a major challenge for the design of inclusive transportation policies.

A final point to be made here is that transportation research, with a combination of qualitative and quantitative methods, can benefit from using a mixed-methods approach. Qualitative and quantitative methods, when used together, can offer a powerful way of helping us understand the complexity of changes occurring today.

Overall, this dissertation contributes to the advancement of research on access to public transit and transport-related social exclusion by providing a conceptual framework for examining the relationship between transport disadvantaged groups and travel, and for understanding the complexity of the relationship between mobility and social exclusion. This research also contributes to the understanding of journey-to-work differences among minority groups over time in the Portland metropolitan area. It seems that gender, class, race, and county of residence are the most significant predictors of the journey-to-work characteristics.

It is indisputable that Portland is further ahead on the sustainable transportation curve than most cities. It has been on the leading edge of progressive sustainable policies. It actually, inspired too many cities around the globe to shift toward sustainable transportation policies. Therefore, it might be that occupying this leading role may help it to shift from a progressive view of sustainability into a progressive view that incorporates 
equity. If Portland is able to inspire the rest of the country, it might be the case that a shift to a more equitable approach will be followed by other cities.

Fighting inequality is a never-ending responsibility of the public sector. In this context, transportation policy-makers in Portland must do a better job in dealing effectively with income inequality and social exclusion. Portland will need to find a better way to balance environmental sustainability and social equity, or suffer the consequences. 


\section{References}

Abbott, Carl. Greater Portland: Urban life and landscape in the Pacific Northwest. University of Pennsylvania Press, 2001.

Abbott, Carl. "The Portland region: Where city and suburbs talk to each other-and often agree." Housing Policy Debate 8.1, 1997, pp. 11-51.

Anbinder, Jacob. 2015. Magic (Disappearing) Bus.

http://www.tcf.org/blog/detail/magic-disappearing-bus (retrived June 15 2016).

Anderson, W. "Structural Funding Problems at the CTA: A Commentary on the RTA Funding Structure and Regional Economic Benefits." CTS Working Papers, (2004): 114.

Arriaga, Eugenio and Silva, Mario. "Between Political Fragmentation and Cooperation: Sustainable Mobility, Institutions, and Regional Planning in Guadalajara, Mexico." Regional Development Dialogue 33.1 (2012): 100-119.

Banister, David. "Equity and acceptability questions in internalising the social costs of transport." Internalising the social costs of transport (1994): 153-175.

Baum-Snow, Nathaniel, Matthew E. Kahn, and Richard Voith. "Effects of urban rail transit expansions: Evidence from sixteen cities, 1970-2000 [with Comment]." Brookings-Wharton papers on urban affairs (2005): 147-206.

Block, Fred. "The ruling class does not rule: Notes on the Marxist theory of the state." Socialist Revolution 33.7 (1977): 6-28.

Blumenberg, Evelyn, and Trevor Thomas. "Travel behavior of the poor after welfare reform." Transportation Research Record: Journal of the Transportation Research Board 2452 (2014): 53-61.

Blumenberg, Evelyn, and Daniel Hess. "Measuring the role of transportation in facilitating welfare-to-work transition: evidence from three California counties." Transportation Research Record: Journal of the Transportation Research Board 1859 (2003): 93-101.

Brueckner, Jan K., and Stuart S. Rosenthal. "Gentrification and neighborhood housing cycles: will America's future downtowns be rich?." The Review of Economics and Statistics 91.4 (2009): 725-743. 
Brueckner, Jan K., Jacques-Francois Thisse, and Yves Zenou. "Why is central Paris rich and downtown Detroit poor?: An amenity-based theory." European economic review 43.1 (1999): 91-107.

Caumont, Andre and Wang, Wendy. 2014. "Pew Research Center. 5 questions (and answers) about American moms today." http://www.pewresearch.org/facttank/2014/05/09/5-questions-and-answers-about-american-moms-today/

Centre for the Research of Social Policy (CRSP) (2009) Presentation of interim findings from evaluation of accessibility planning in the $U K 20^{\text {th }}$ November, 2009. Department of Transport, Marsham Street, London WC1.

Cervero, Robert. The transit metropolis: a global inquiry. Island press, 1998.

Cervero, Robert, and Yu-Hsin Tsai. "Job access and reverse commuting initiatives in California: Review and assessment." Transportation Research Record: Journal of the Transportation Research Board 1859 (2003): 78-86.

Cervero, Robert, Onésimo Sandoval, and John Landis. "Transportation as a stimulus of welfare-to-work: Private versus public mobility." Journal of Planning Education and Research 22.1 (2002): 50-63.

Cervero, Robert. America's suburban centers: the land use-transportation link. Routledge, 1989.

Church, Andrew, Martin Frost, and Karen Sullivan. "Transport and social exclusion in London." Transport Policy 7.3 (2000): 195-205.

Cichocki, Mary K. "Women's travel patterns in a suburban development." New space for women (1980): 151-64.

Clark, David L. "Improbable Los Angeles." (1983): 268-308 in Bernard, Richard M., and Bradley R. Rice, eds. Sunbelt cities: Politics and growth since World War II. University of Texas Press, 2014.

Clifton, Kelly J., and Karen Lucas. "Examining the empirical evidence of transport inequality in the US and UK." (2004). In K. Lucas, editor, Running on Empty: Transport, Social Exclusion and Environmental Justice. Bristol, U.K.: Policy Press, 15-38.

Crane, Randall. "Is there a quiet revolution in women's travel? Revisiting the gender gap in commuting." Journal of the American planning association 73.3 (2007): 298-316. 
Crane, Randall, and Lois Takahashi. "Sex changes everything the recent narrowing and widening of travel differences by gender." Public works management \& policy 13.4 (2009): 328-337.

Currie, Graham, and Janet Stanley. No way to go: Transport and social disadvantage in Australian communities. Monash University, 2007.

Currie, Graham. "Gap analysis of public transport needs: measuring spatial distribution of public transport needs and identifying gaps in the quality of public transport provision." Transportation Research Record: Journal of the Transportation Research Board 1895 (2004): 137-146.

Currie, Graham, ed. New perspectives and methods in transport and social exclusion research. Emerald Group Publishing Limited, 2011.

Davey, Judith A. "Older people and transport: coping without a car." Ageing and Society 27.01 (2007): 49-65.

Davis, Shannon N. "Gender ideology construction from adolescence to young adulthood." Social Science Research 36.3 (2007): 1021-1041.

Davis, Shannon N., and Theodore N. Greenstein. "Gender ideology: Components, predictors, and consequences." Annual Review of Sociology 35 (2009): 87-105.

Deen, Thomas. "Policy versus the market: transportation's battleground." Transportation Research Record: Journal of the Transportation Research Board 1839 (2003): 5-22.

Delbosc, Alexa, and Graham Currie. "The spatial context of transport disadvantage, social exclusion and well-being." Journal of Transport Geography 19.6 (2011): 11301137.

DeLuca, Cathy. "Do Women Have Equal Opportunity to Influence Bicycle Planning Policy?." Disertation. San José State University, 2011.

Dill, Jennifer; Bates, Lisa; Warr, Jake; and Arriaga, Eugenio. Understanding the TransitDependent Population. Technical Report. Portland State University. 2014.

Dodson, Jago, et al. "Travel Behavior Patterns of Different Socially Disadvantaged Groups: Analysis of Household Travel Survey Data for a Dispersed Metropolitan Area." Transportation Research Record: Journal of the Transportation Research Board 2163 (2010): 24-31.

Dodson, Jago, Brendan Gleeson, and Neil G. Sipe. Transport disavantage and social status: a review of literature and methods. Australia: Urban Policy Program, Griffith University, 2004. 
England, Kim VL. "Suburban pink collar ghettos: the spatial entrapment of women?." Annals of the Association of American Geographers 83.2 (1993): 225-242.

Fainstein, Susan S. The just city. Cornell University Press, 2010.

Farmer, Stephanie, and Sean Noonan. "The contradictions of capital and mass transit: Chicago, USA." Science \& Society 78.1 (2014): 61-87.

Farmer, Stephanie. "Uneven public transportation development in neoliberalizing Chicago, USA." Environment and Planning A 43.5 (2011): 1154-1172.

Farmer, Stephanie. " On the Move The Neoliberalization of US Public Transportation." Harvard International Review 35.2 (2013): 60.

Forer, P. C., and Helen Kivell. "Space-Time Budgets, Public Transport, and Spatial Choice." Environment and Planning A 13.4 (1981): 497-509.

Friiim, I. "2000 HHS Poverty Guidelines." Federal Register 65.31 (2000): 7555-7557.

Fritze, Jess. "You might as well just stay at home." (2007).

Gavron, Hannah. The captive wife: Conflicts of housebound mothers. London: Routledge \& Kegan Paul, 1966.

Gibson, Karen. "Urban redevelopment in Portland: Making the city livable for everyone." The Portland edge: Challenges and successes in growing communities (2004): 61-83.

Gibson, Karen J. "Bleeding Albina: A History of Community Disinvestment, 19402000." Transforming Anthropology 15.1 (2007): 3-25.

Gibson, Karen J. "Problems of racial justice in Portland, 1968-2010: Revisiting the city's "Kerner report"." Reinventing race, reinventing racism 50 (2012): 81.

Gilbert, Melissa. "Place, politics, and the production of urban space: A feminist critique of the growth machine thesis." The urban growth machine: Critical perspectives, two decades later (1999): 95-108.

Giuliano, Genevieve. "Low income, public transit, and mobility." Transportation Research Record: Journal of the Transportation Research Board 1927 (2005): 63-70. 
Giuliano, Genevieve. "Residential Location Differences in People of Color." Travel Patterns of People of Color. Prepared by Battelle Memorial Institute for the Federal Highway Administration, 2000.

Giuliano, Genevieve. "Public transportation and the travel needs of women." Traffic Q.;(United States) 33.4 (1979).

Giuliano, Genevieve, and Kenneth A. Small. "Is the journey to work explained by urban structure?." Urban studies 30.9 (1993): 1485-1500.

Glaeser, Edward L., Matthew E. Kahn, and Jordan Rappaport. "Why do the poor live in cities? The role of public transportation." Journal of urban Economics 63.1 (2008): 1-24.

Gleeson, Brendan, and Bill Randolph. "Social disadvantage and planning in the Sydney context." Urban Policy and Research 20.1 (2002): 101-107.

Goddard, Tara, et al. "Voyage of the SS Minivan: Women's travel behavior in traditional and suburban neighborhoods." Transportation Research Record: Journal of the Transportation Research Board 1956 (2006): 141-148.

Goodling, Erin, Jamaal Green, and Nathan McClintock. "Uneven development of the sustainable city: Shifting capital in Portland, Oregon." Urban Geography 36.4 (2015): 504-527.

Golob, Thomas F., and Michael G. McNally. "A model of activity participation and travel interactions between household heads." Transportation Research Part B:

Methodological 31.3 (1997): 177-194.

Gordon, David, et al. "Poverty and social exclusion in Britain." (2000).

Gossen, Rachel, and Charles L. Purvis. "Activities, time, and travel." Research on Women's Issues in Transportation (2005): 21.

Grengs, Joe. "The abandoned social goals of public transit in the neoliberal city of the USA." City 9.1 (2005): 51-66.

Grengs, Joe. "Measuring change in small-scale transit accessibility with Geographic Information Systems: Buffalo and Rochester, New York." Transportation Research Record: Journal of the Transportation Research Board 1887 (2004): 10-17.

Hallowell, Alexandra, and Kelan Stoy. "The Rent Is Too Damn High: Parking and Affordability in Portland, Oregon." Berkeley, CA (2014).

Harvey, David. A brief history of neoliberalism. Oxford University Press, USA, 2007. 
Harvey, David. Social justice and the city. Vol. 1. University of Georgia Press, 2010.

Handy, Susan, Lisa Weston, and Patricia L. Mokhtarian. "Driving by choice or necessity?." Transportation Research Part A: Policy and Practice 39.2 (2005): 183-203.

Handy, Susan, et al. "Residential location choice and travel behavior: Implications for air quality." Prepared for the California Department of Transportation, Davis, CA (2004).

Hanson, Susan. "Gender and mobility: new approaches for informing sustainability." Gender, Place \& Culture 17.1 (2010): 5-23.

Hanson, Susan, and Perry Hanson. "The impact of married women's employment on household travel patterns: A Swedish example." Transportation 10.2 (1981): 165-183.

Hodgson, F. C., and J. Turner. "Participation not consumption: the need for new participatory practices to address transport and social exclusion." Transport Policy 10.4 (2003): 265-272.

Hogan, Bernie, and Brent Berry. 2011. "Racial and Ethnic Biases in Rental Housing: An Audit Study of Online Apartment Listings.” City \& Community 10: 51-72.

Hurni, Anne. "Transport and social disadvantage in Western Sydney: a partnership research project." Western Sydney Community Forum (2006)

Hurni, Anne. "Transport and social exclusion in Western Sydney." Transporting the Future: Transport in a Changing Environment: Conference Proceedings of the 28th Australasian Transport Research Forum. 2005.

Hurni, Anne. "Marginalised groups in Western Sydney: The experience of sole parents and unemployed young people." Dissertation. (2007).

Ihlanfeldt, Keith R., and David L. Sjoquist. "The spatial mismatch hypothesis: a review of recent studies and their implications for welfare reform." Housing policy debate 9.4 (1998): 849-892.

Jones, P. M. Mobility and the individual in western industrial society. Transport Research Laboratory. No. TSU REF: 2, 1984.

Jones, Peter. "Conceptualising Car 'Dependence'." Auto Motives: Understanding Car Use Behaviours. Emerald Group Publishing Limited, 2011. 39-61.

JUSTICE, VIEWS ON SOCIAL. "CHAPTER, 2 Social and Environmental Justice Issues in Urban Transportation." The geography of urban transportation (2004): 332. 
Karner, Alex, and Deb Niemeier. "Civil rights guidance and equity analysis methods for regional transportation plans: a critical review of literature and practice." Journal of Transport Geography 33 (2013): 126-134.

Krovi, Ravindra, and Claude Barnes. "Work-related travel patterns of people of color." Travel Patterns of People of Color 45 (2000).

Kwan, Mei-Po. "Gender, the home-work link, and space-time patterns of non employment activities." Economic geography 75.4 (1999): 370-394.

Lang, Robert E., and Steven P. Hornburg. "Planning Portland style: Pitfalls and possibilities." Housing Policy Debate 8.1 (1997): 1-10.

Lau, Joseph CY. "Accessibility and the coping behaviour of the non-employed people in Hong Kong." Habitat International 30.4 (2006): 1047-1055.

Law, Robin. "Beyond 'women and transport': towards new geographies of gender and daily mobility." Progress in human geography 23.4 (1999): 567-588.

Logan, John R., and Harvey Molotch. Urban fortunes: The Political Economy of Place. Univ of California, 2007.

Lopata, Helena Znaniecki. "Widowhood and husband sanctification." Journal of Marriage and the Family (1981): 439-450.

Lorber, Judith. Gender inequality: Feminist theories and politics. New York: Oxford University Press, 2010.

Lucas, Karen. "Providing transport for social inclusion within a framework for environmental justice in the UK." Transportation Research Part A: Policy and Practice 40.10 (2006): 801-809.

Lucas, Karen. "The role of transport in the social exclusion of low income populations in South Africa: a scoping study." Proceeding of Transportation Research Board Annual Meeting. Vol. 1015. 2010.

Lucas, Karen. "Transport and social exclusion: Where are we now?." Transport policy 20 (2012): 105-113.

Lucas, Karen, Tim Grosvenor, and Roona Simpson. Transport, the environment and social exclusion. York Publishing Services Limited, 2001.

Lucas, Karen, and Graham Currie. "Developing socially inclusive transportation policy: transferring the United Kingdom policy approach to the State of Victoria?." Transportation 39.1 (2012): 151-173. 
MacDonald, Heather I. "Women's employment and commuting: explaining the links." CPL bibliography 13.3 (1999): 267-283.

McLafferty, Sara, and Valerie Preston. "Gender, race, and commuting among service sector workers." The Professional Geographer 43.1 (1991): 1-15.

Madden, Janice Fanning. "Why women work closer to home." Urban studies 18.2 (1981): 181-194.

Mandanipour, Ali, Goran Cars, and Judith Allen. "Social exclusion in European cities." London: Jessica Kingsley, 1998.

Marcuse, Peter, and Ronald van Kempen. "Conclusion: A changed spatial order." Globalizing Cities: A New Spatial Order? (2000): 249-275.

Massey, Douglas S. "The age of extremes: Concentrated affluence and poverty in the twenty-first century." Demography 33.4 (1996): 395-412.

Massey, Douglas S., and Nancy A. Denton. 1993. American Apartheid: Segregation and the Making of the Underclass. Cambridge: Harvard University Press.

Mauch, Michael, and Brian Taylor. "Gender, race, and travel behavior: Analysis of household-serving travel and commuting in San Francisco bay area." Transportation Research Record: Journal of the Transportation Research Board 1607 (1997): 147-153.

Mayer, Heike. 2005. "Taking Root in the Silicon Forest: High Technology Firms as Surrogate Universities in Portland, OR." Journal of the American Planning Association $71: 318-33$.

McGuckin, Nancy, and Elaine Murakami. "Examining trip-chaining behavior: Comparison of travel by men and women." Transportation Research Record: Journal of the Transportation Research Board 1693 (1999): 79-85.

McKenzie, Brian S. "Neighborhood access to transit by race, ethnicity, and poverty in Portland, OR." City \& Community 12.2 (2013): 134-155.

McKenzie, Brian, and Melanie Rapino. Commuting in the united states: 2009. Washington, DC: US Department of Commerce, Economics and Statistics Administration, US Census Bureau, 2011.

McLafferty, Sara, and Valerie Preston. "Gender, race, and commuting among service sector workers." The Professional Geographer 43.1 (1991): 1-15. 
Miles, Rebecca, and Yan Song. "“Good" neighborhoods in Portland, Oregon: Focus on both social and physical environments." Journal of Urban Affairs 31.4 (2009): 491-509.

Molotch, Harvey. "The city as a growth machine: Toward a political economy of place." American journal of sociology 82.2 (1976): 309-332.

Mollenkopf, Heidrun, et al. "Social and behavioural science perspectives on out-of-home mobility in later life: findings from the European project MOBILATE." European Journal of Ageing 1.1 (2004): 45-53.

Morgan, Travers. "Strategies to overcome transport disadvantage." Canberra, Department of the Prime Minister and Cabinet Social Justice Research Programme into Locational Disadvantage (1992).

Murray, Alan T., and Rex Davis. "Equity in regional service provision." Journal of Regional Science 41.4 (2001): 557-600.

Pastor Jr, Manuel, Chris Benner, and Martha Matsuoka. This could be the start of something big: How social movements for regional equity are reshaping metropolitan America. Cornell University Press, 2015.

Peng, Zhong-Ren. "The jobs-housing balance and urban commuting." Urban studies 34.8 (1997): 1215-1235.

Pickup, Laurie. "Women's gender-role and its influence on travel behaviour." Built Environment (1978) (1984): 61-68.

Pickup, Laurie. "Hard to get around: a study of women's travel mobility." Women in Cities. Macmillan Education UK, 1988. 98-116.

Pratt, Geraldine, and Susan Hanson. "On the Links between Home and Work: FamilyHousehold Strategies in a Buoyant Labour Market." International journal of urban and regional research 15.1 (1991): 55-74.

Preston, Valerie, Sara McLafferty, and Ellen Hamilton. "The impact of family status on black, white, and Hispanic women's commuting." Urban geography 14.3 (1993): 228250 .

Rajé, Fiona, et al. Transport, demand management and social inclusion: The need for ethnic perspectives. Ashgate, 2004.

Raphael, Steven, and Lorien Rice. "Car ownership, employment, and earnings." Journal of Urban Economics 52.1 (2002): 109-130. 
Rapino*, Melanie A., and Thomas J. Cooke. "Commuting, gender roles, and entrapment: A national study utilizing spatial fixed effects and control groups." The Professional Geographer 63.2 (2011): 277-294.

Renwick, Trudi, et al. "Supplemental Poverty Measure: A Comparison of Geographic Adjustments with Regional Price Parities vs. Median Rents from the American Community Survey." (2014).

Rosenbloom, Sandra. "Understanding women's and men's travel patterns." Research on Women's Issues in Transportation. 2006.

Rosenbloom, Sandra. "The need for study of women's travel issues." Transportation 7.4 (1978): 347-350.

Rutherford, Brent M., and Gerda R. Wekerle. "Captive rider, captive labor: spatial constraints and women's employment." Urban Geography 9.2 (1988): 116-137.

Sanchez, Thomas W. "Poverty, policy, and public transportation." Transportation Research Part A: Policy and Practice 42.5 (2008): 833-841.

Sellinger, Philip. "Making History 45 Years of TRIMET and Transit in the Portland Region.” TriMet (2015): 1-100.

Sen, Siddhartha. "Environmental justice in transportation planning and policy: A view from practitioners and other stakeholders in the Baltimore-Washington, DC metropolitan region." Journal of Urban Technology 15.1 (2008): 117-138.

Shaw, Samuel, and Daniel Monroe Sullivan. "“White Night": Gentrification, racial exclusion, and perceptions and participation in the arts." City \& Community 10.3 (2011): 241-264.

Sivak, Michael. "Has motorization in the US peaked? Part 4: Households without a lightduty vehicle." (2014).

Soja, Edward W. Seeking spatial justice. Vol. 16. U of Minnesota Press, 2010.

Stanley, John. "Improving public transport to meet community needs: A Warrnambool case-study." (2004).

Taylor, Brian D., Kelcie Ralph, and Michael Smart. "What Explains the Gender Gap in Schlepping? Testing Various Explanations for Gender Differences in Household-Serving Travel." Social Science Quarterly 96.5 (2015): 1493-1510. 
Theriault, Marius, Marie-Helene Vandersmissen, and Paul Villeneuve. "Work Trips: Are There Still Gender Differences? Case of Quebec Metropolitan Area, 1991 and 2001." Transportation Research Board 85th Annual Meeting. No. 06-0201. 2006.

Tivers, Jacqueline. "How the other half lives: the geographical study of women." Area (1978): 302-306.

Tivers, Jacqueline. Women attached: the daily lives of women with young children. Croom-Helm, 1985. United States. Census Bureau. Population Division. “American Factfinder II, detailed tables." United States Census 2011. Washington: US Census Bureau. www.factfinder2.census.gov.

United States. Census Bureau. Population Division. "Quick facts." United States Census 2012. Washington: US Census Bureau. http://quickfacts.census.gov.

United States. Census Bureau. Population Division. "American Factfinder II, detailed tables." United States Census 2000. Washington: US Census Bureau.

United States. Census Bureau. Population Division. "American Community Survey 5 year estimates." United States Census 2008-2012. Washington: US Census Bureau.

United States. Census Bureau. Population Division. "Social Explorer Tables: Census 2010.” United States Census 2010. Washington: US Census Bureau.

Wachs, Martin. "Transportation policy, poverty, and sustainability: history and future." Transportation Research Record: Journal of the Transportation Research Board 2163 (2010): 5-12.

Wachs, Martin, and T. Gordon Kumagai. "Physical accessibility as a social indicator." Socio-Economic Planning Sciences 7.5 (1973): 437-456.

Wickham, James, and Maria Lohan. "The Transport Rich and the Transport Poor: Car dependency and social class in four European cities." National University of Ireland, Maynooth (1999).

Wixey, Sarah, et al. "Measuring accessibility as experienced by different socially disadvantaged groups." London, Transit Studies Group, University of Westminster (2005).

Woodward, Val. "Transport Disadvantage and Social Exclusion: Exclusionary Mechanisms in Transport in Urban Scotland, Julian Hine and Fiona Mitchell, Ashgate, Aldershot,(2003)." (2004): 252-253. 
Wright, Erik Olin. Approaches to class analysis. Cambridge University Press, 2005.

Wright, Erik Olin. Class counts: Comparative studies in class analysis. Cambridge University Press, 1997.

Wright, Erik Olin. "The continuing relevance of class analysis-comments." Theory and Society 25.5 (1996): 693-716.

Yago, Glenn. The decline of transit: urban transportation in German and US cities, 1900-1970. Cambridge University Press, 1984. 


\section{Appendix}

\section{Socio-Demographic Trends in the Portland Metropolitan Area}

\section{$\underline{\text { Race and residential location (by county) }}$}

Historically, Blacks and Latinos have followed different patterns of population growth in the Portland Metropolitan area (Clackamas, Multnomah, and Washington Counties). Blacks have accounted for about $3 \%$ of the Portland population since 1990. Their population decreased from $3.2 \%$ in 1990 to $3.0 \%$ in 2000 , then increased to $3.1 \%$ in 2010 .

Table 1: Metro population change by race/ethnicity in Portland Metro, Oregon.

\begin{tabular}{lcccccc}
\hline Statistics & \multicolumn{2}{c}{ Census 1990} & \multicolumn{2}{c}{ Census 2000 } & \multicolumn{2}{c}{ Census 2010 } \\
\hline Population & $1,174,291$ & $\%$ & $1,444,219$ & $\%$ & $1,641,036$ & $\%$ \\
White & $1,041,904$ & 88.7 & $1,153,291$ & 79.9 & $1,217,404$ & 74.2 \\
Black & 37,508 & 3.2 & 43,426 & 3.0 & 51,541 & 3.1 \\
Latino & 39,920 & 3.4 & 116,086 & 8.0 & 192,546 & 11.7 \\
\hline
\end{tabular}

Source: Social Explorer Tables (SE), Census 1990, 2000 and 2010, Census Bureau; Social Explorer; OTAS 2011 and POTAS 1994. Results do not add to $100 \%$ because only a few racial categories are shown.

In terms of residential location, between 2000 and 2010 the share of Blacks living at the periphery of the city increased from $37 \%$ to $43 \%$ (U.S. Census Bureau, 2011), while the population of Blacks living in Multnomah County (which encompasses Portland) decreased from $5.9 \%$ of the total population in 1990 to $5.4 \%$ in 2010 (see Table 2). In contrast, the proportion of Blacks increased in all the neighboring suburban counties (Clackamas and Washington).

Table 2: Portland Metro population changes by race 1990, 2000, and 2010

\begin{tabular}{lccccc}
\hline County & Year & Population & White & Black & Hispanic \\
\hline \multirow{3}{*}{ Clackamas } & 1990 & 278,850 & $263,965(94.7 \%)$ & $1,107(0.4)$ & $7,129(2.6)$ \\
& 2000 & 338,391 & $301,548(89.1)$ & $2,056(0.6)$ & $16,744(5.0)$ \\
& 2010 & 375,992 & $317,648(84.5)$ & $2,761(0.7)$ & $29,138(7.8)$ \\
\cline { 2 - 6 } Multnomah & 1990 & 583,887 & $497,700(85.2)$ & $34,415(5.9)$ & $18,390(3.2)$ \\
& 2000 & 660,486 & $505,492(76.5)$ & $36,592(5.5)$ & $49,607(7.5)$ \\
& 2010 & 735,334 & $530,303(72.1)$ & $39,919(5.4)$ & $80,138(10.9)$ \\
\cline { 2 - 5 } Washington & 1990 & 311,554 & $280,239(90.0)$ & $1,986(0.6)$ & $14,401(4.6)$ \\
& 2000 & 445,342 & $346,251(77.8)$ & $4,778(1.1)$ & $49,735(11.2)$ \\
& 2010 & 529,710 & $369,453(69.8)$ & $8,861(1.7)$ & $83,270(15.7)$ \\
\hline
\end{tabular}

Sources: Social Explorer Tables (SE), Census 1990, 2000 and 2010, Census Bureau; Social Explorer

Latinos in Portland have followed a different population growth pattern than Blacks. Since the 1990's the Latino proportion of the population has increased in Metro Portland, from $3.4 \%$ in 1990 to $11.7 \%$ in 2010 (see Tables 1 and 2). The state of Oregon has had a long history of Latino seasonal in-migration stimulated by governmental agricultural programs, such as the Special Agricultural Workers program (SAW). By 2010 there were 450,052 
Latinos in Oregon, of which almost 70\% lived in urban areas. In 2011 there were around 160,000 undocumented immigrants in Oregon, with approximately 60 to 75 percent of them from Mexico.

\section{Poverty rates (by race)}

Poverty changes for the analyzed minority groups between 1990 and 2013 are presented in Table 3. Poverty rates decreased from 1990 to 2000 and then increased by 2013 , perhaps as a factor of the economic recession of 2009. In 2013 Blacks had the highest share below poverty (34\%), followed by Latinos (27.6\%), and then Whites $(10.8 \%)$.

Table 3: Portland Metro population below poverty by race/ethnicity

\begin{tabular}{lcccccc}
\hline Statistics & Census 1990 & \multicolumn{3}{c}{ Census 2000 } & \multicolumn{3}{c}{ ACS 2013 (5 Years) } \\
\hline Income below poverty & $\mathrm{N}$ & $\%$ & $\mathrm{~N}$ & $\%$ & $\mathrm{~N}$ & $\%$ \\
White & 89,438 & 8.5 & 84,188 & 7.4 & 130,719 & 10.8 \\
Black & 10,775 & 29.4 & 9,689 & 23.6 & 18,351 & 34.1 \\
Hispanic & 9,243 & 24.6 & 26,050 & 22.9 & 53,689 & 27.6 \\
\hline
\end{tabular}

Sources: Census 1990 and 2000 Census Bureau; Social Explorer; ACS 2013 (5-Year Estimates), Social

Explorer; U.S. Census Bureau

\section{Commuting to work: transportation mode (by race)}

Table 4 shows changes in commuting to work transportation mode for the study's sample population, between 1994 and 2011. Blacks have the highest use of public transit: 17\% average in the two periods, though $29 \%$ in 2011.

Table 4: Sample population driving alone \& using public transit to work, by race, 1994 and 2011

\begin{tabular}{|c|c|c|c|c|c|c|c|}
\hline \multicolumn{2}{|c|}{ Mode to work } & \multicolumn{6}{|c|}{ Public transit } \\
\hline & & \multicolumn{2}{|c|}{1994} & \multicolumn{2}{|c|}{2011} & \multicolumn{2}{|c|}{ Average } \\
\hline Race & Gender & $\mathrm{M}$ & $\mathrm{N}$ & $\mathrm{M}$ & $\mathrm{N}$ & $\mathrm{M}$ & $\mathrm{N}$ \\
\hline \multirow[t]{3}{*}{ White } & Male & 9.7 & 2374 & 12.7 & 2167 & 11.1 & 4541 \\
\hline & Female & 12.3 & 2125 & 14.1 & 2223 & 13.2 & 4348 \\
\hline & Total & 11.0 & 4499 & 13.4 & 4390 & 12.1 & 8889 \\
\hline \multirow[t]{3}{*}{ Black } & Male & 11.1 & 36 & 29.4 & 17 & 17.0 & 53 \\
\hline & Female & 24.1 & 29 & 24.0 & 25 & 24.1 & 54 \\
\hline & Total & 17.0 & 65 & 26.1 & 42 & 20.5 & 107 \\
\hline \multirow{3}{*}{ Latino } & Male & 9.4 & 32 & 11.7 & 77 & 11.0 & 109 \\
\hline & Female & 23.5 & 17 & 18.8 & 69 & 19.7 & 86 \\
\hline & Total & 14.3 & 49 & 15.0 & 146 & 14.9 & 195 \\
\hline \multirow[t]{3}{*}{ Total } & Male & 9.7 & 2442 & 12.8 & 2261 & 11.2 & 4703 \\
\hline & Female & 12.5 & 2171 & 14.4 & 2317 & 13.5 & 4488 \\
\hline & Total & 11.0 & 4613 & 13.6 & 4578 & 12.3 & 9191 \\
\hline \multicolumn{2}{|c|}{ Mode to work } & \multicolumn{6}{|c|}{ Drive alone } \\
\hline & & \multicolumn{2}{|c|}{1994} & \multicolumn{2}{|c|}{2011} & \multicolumn{2}{|c|}{ Average } \\
\hline \multirow{3}{*}{$\begin{array}{l}\text { Race } \\
\text { White }\end{array}$} & Gender & $\mathrm{M}$ & $\mathrm{N}$ & $\mathrm{M}$ & $\mathrm{N}$ & $\mathrm{M}$ & $\mathrm{N}$ \\
\hline & Male & 71.2 & 2374 & $\overline{73.1}$ & 2167 & 72.1 & 4541 \\
\hline & Female & 69.5 & 2125 & 74.1 & 2223 & 71.8 & 4348 \\
\hline
\end{tabular}




\begin{tabular}{llcc|cc|cc}
\multirow{5}{*}{ Black } & Total & 70.4 & 4499 & 73.6 & 4390 & 72.0 & 8889 \\
\cline { 2 - 8 } & Male & 77.8 & 36 & 70.6 & 17 & 75.4 & 53 \\
& Female & 51.7 & 29 & 76.0 & 25 & 63.0 & 54 \\
Latino & Total & 66.1 & 65 & 73.8 & 42 & 69.1 & 107 \\
\cline { 2 - 8 } & Male & 62.5 & 32 & 71.4 & 77 & 68.8 & 109 \\
& Female & 76.4 & 17 & 71.0 & 69 & 72.1 & 86 \\
& Total & 67.3 & 49 & 71.2 & 146 & 70.2 & 195 \\
\cline { 2 - 7 } Total & Male & 71.2 & 2442 & 73.0 & 2261 & 72.0 & 4703 \\
& Female & 69.3 & 2171 & 74.0 & 2317 & 71.8 & 4488 \\
& Total & 70.3 & 4613 & 73.5 & 4578 & 71.9 & 9191 \\
\hline
\end{tabular}

Sources: POTAS, (1994); OTAS, (2011).

\section{Jobs-housing mismatch (by race)}

Table 5 shows the share of workers living and working in the same county in metropolitan Portland, during 2011.

Table 5: Share of workers living and working in the same county in Portland Metro, 2011

\begin{tabular}{lc}
\hline Race & $\begin{array}{c}\text { Share of workers living \& } \\
\text { working in same county, 2011 }\end{array}$ \\
\hline & $\%$ \\
White & 67.0 \\
Blacks & 58.0 \\
Hispanic & $66 \%$ \\
\hline
\end{tabular}

Sources: OTAS, (2011).

\section{Distribution of activities (by gender and family type)}

Table 6 shows the distribution of household, work, and discretionary activities of sample members (1994 and 2011 average) by type of family and gender.

Table 6: Distribution of activities by family type and gender (1994 \& 2011 average)

\begin{tabular}{lccccc}
\hline \multicolumn{1}{c}{ 1994-2011 } & One person & Couples no- & Single Parent & Couples with & Total \\
& HH & children HH & HH & children & \\
\hline Work & 998 & Males & & & \\
Percentage & $20 \%$ & 19 & 24 & 2475 & 5814 \\
HH tasks & 870 & 2278 & 86 & 1982 & 5216 \\
Percentage & 17 & 20 & 25 & 21 & 20 \\
Discretionary & 2223 & 4761 & 132 & 3083 & 10199 \\
Percentage & 45 & 41 & 38 & 32 & 39 \\
Other & 784 & 2339 & 48 & 2042 & 5213 \\
Percentage & 16 & 20 & 14 & 21 & 20 \\
Total & 4875 & 11637 & 348 & 9582 & 26442 \\
\hline \multicolumn{7}{c}{} & Females & & & 4992 \\
\hline Work & 1174 & 1956 & 217 & 1645 & 15 \\
Percentage & $16 \%$ & 16 & 14 & 14 & 8957 \\
HH tasks & 1655 & 2764 & 504 & 4034 &
\end{tabular}




\begin{tabular}{lccccc} 
Percentage & 23 & 23 & 32 & 34 & 27 \\
Discretionary & 2945 & 4914 & 632 & 3554 & 12045 \\
Percentage & 40 & 41 & 40 & 30 & 37 \\
Other & 1501 & 2404 & 229 & 2620 & 6754 \\
Percentage & 21 & 20 & 14 & 22 & 21 \\
Total & 7275 & 12038 & 1582 & 11853 & 32748 \\
\hline \multicolumn{7}{c}{ All } & 4215 & 299 & 4120 & 10806 \\
\hline Work & 2172 & 18 & 15 & 19 & 18 \\
Percentage & 18 & 5042 & 590 & 6016 & 14173 \\
HH tasks & 2525 & 21 & 31 & 28 & 24 \\
Percentage & 21 & 9675 & 764 & 6637 & 2244 \\
Discretionary & 5168 & 41 & 40 & 31 & 38 \\
Percentage & 43 & 4743 & 277 & 4662 & 11967 \\
Other & 2285 & 20 & 14 & 22 & 20 \\
Percentage & 19 & 23675 & 1930 & 21435 & 59190 \\
Total & 12150 & & & & \\
\hline
\end{tabular}

Results showed that overall: 1) males in all the family type categories worked more than females, and that males with children had a higher share of work activities than men without children; 2) the highest gender gap in work related activities was among households with children, particularly within the "couples with children" category, where men's work-related activities were double that of women (26\% vs $14 \%)$.

In contrast, in keeping with to the "gender socialization" hypothesis, women's share of household maintenance activities as a share of all activities was higher than males in every family category; although, the sharpest differences were among women with children, particularly within couples with children.

Interestingly, the share of household activities among males from the family categories "couples with children" and without children" was very similar (21\% and $20 \%)$, suggesting that the additional work related to childbearing rests mostly on women. As expected, the lowest gender gap in both household maintenance and work related activities was among childless households.

Table 7: Trip purpose attributes by family type (sample population).

\begin{tabular}{clcccccc}
\hline & & All & \multicolumn{3}{c}{ Men } & \multicolumn{3}{c}{ Female } \\
& Type of household & $\mathrm{N}$ & Mean & $\mathrm{N}$ & Mean & $\mathrm{N}$ & Mean \\
\hline \# Work trips & One person & 1087 & 2.5 & 484 & 2.4 & 603 & 2.6 \\
& Couples no-children & 1980 & 2.5 & 1015 & 2.5 & 963 & 2.4 \\
& Single-parent & 118 & 2.3 & 25 & 2.6 & 93 & 2.2 \\
& Couples with-children & 1779 & 2.3 & 1070 & 2.4 & 709 & 2.2 \\
& Total & 4964 & 2.4 & 2594 & 2.5 & 2368 & 2.4 \\
Work trip total & One person & 2216 & 5.5 & 895 & 6.2 & 1321 & 5.0 \\
distance (miles) & Couples no-children & 4316 & 6.5 & 2169 & 7.6 & 2145 & 5.4 \\
& Single-parent & 295 & 4.4 & 55 & 9.2 & 240 & 3.4 \\
& Couples with-children & 3682 & 7.7 & 1837 & 10.8 & 1845 & 4.5 \\
& Total & 10509 & 6.6 & 4956 & 8.6 & 5551 & 4.9 \\
Work trip total & One person & 2216 & 27.1 & 895 & 28.8 & 1321 & 26.0
\end{tabular}




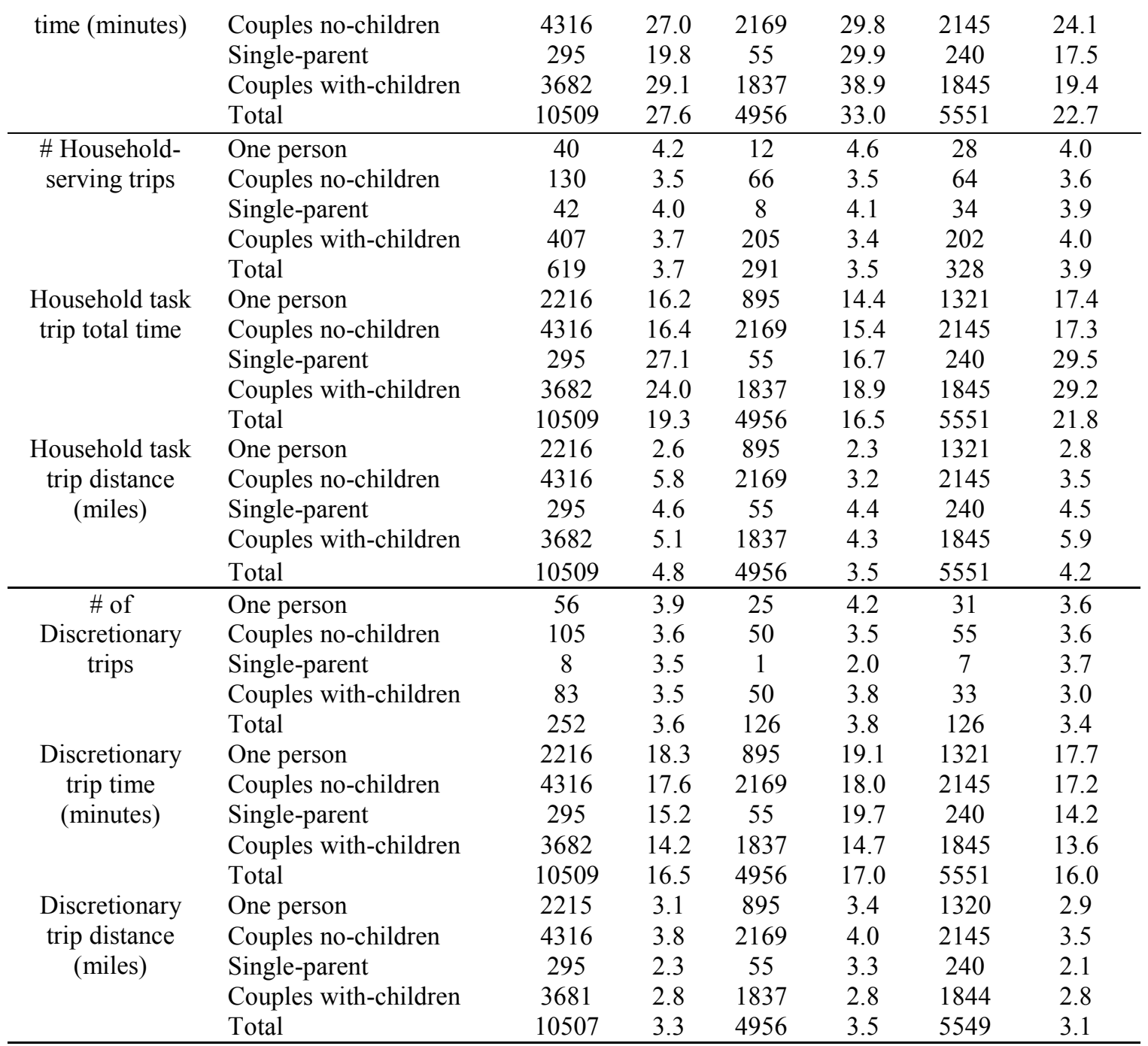

